\title{
The Unrestricted Interest and Its Impact On Sharia Politics
}

\author{
Khalid Mohammed Jassim \\ Department of Islamic Education, College of Basic Education, Al-Mustansiriya University, Iraq \\ dkhaled662@gmail.com
}

\begin{abstract}
:
The study of the unrestricted interests has its importance and position, and this importance and prestige also derives from the challenges of the current era and its various requirements and incidents. It has been decided that a transfer and work, past and present, of the sending interests is an effective importance in understanding the rulings, carrying out the costs, drawing up the method of jurisprudence and applying it in all areas of life, conditions ' issues and demands. It has been learned that the legal policy is the jurisprudence of interests that are required by the conditions of the nation at every time and place, and since the rules of the legal policy work in what has a special text and what is not in it, and the unrestricted interest works in what is not stipulated in it, so it is a wide field to consider the provisions of the legitimate policy and ijtihad in Its points of view in order to clarify the public interests in which the guardian works. This research shows one of the sources of deduction dependent on Islamic legislation, which is the unrestricted interest in its capacity to deal with emerging issues, which comes out of the womb of ijtihad based on looking at the purposes of the Sharia, and this is the science of Sharia policy based on interest.
\end{abstract}

Keywords: $\quad$ Unrestricted Interests; Politics; Sharia; Rulings; Impact.

Crossref doi https://doi.org/10.51345/.v32i1.214.g198 


\title{
المصلحة المرسلة وأثرها في السياسة الشرعية
}

\author{
أ.م.د. خالد محمد جاسم \\ قسم التربية الإسلامية، كلية التربية الأساسية، الجامعة المستنصرية، العراق \\ dkhaled662@gmail.com
}

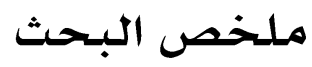

ان دراسة المصالح المرسلة لما أهميتها ومكانتها، وهذه الأهمية والمكانة تستمد ايضاً من تحديات العصر الحالي ومتطلباته وحوادثه المختلفة. وقد تقرر نقلاً وعملاً قديحاً وحديثاً ما للمصالح المرسلة أهمية فعالة في فهم الأحكام والقيام بالتكاليف ورسم منهج الاجتهاد وتطبيقه وفي جميع بجالات الحياة واحوالها وقضاياها ومطالبها. وقد علم ان السياسة الشرعية هي فقه المصالح التي تقتضيها ظروف الأمة في كل زمان ومكان، وبها ان قواعد السياسة الشرعية تعمل فيها فيه نص خاص وفيا لا نص فيه، والمصلحة المرسلة تعمل فيال لا نص فيه، فهي مجال فسيح للنظر في احكام السياسة الشرعية والاجتهاد في مظانها لأجل بيان المصالح العامة التي يعمل بها أولي الأمر. وهذا البحث يبين أحد مصادر الاستنباط التبعية للتشريع الاسلامي وهو المصلحة المرسلة في صلاحيتها لمعالجة القضايا المستجدة، والذي يخرج من رحم الاجتهاد القائم على النظر المى مقاصد الشريعة، وهذا هو علم السياسة الثرعية القائمة على المصلحة.

الكلمات المفتاحية: المصالح المرسلة، السياسة، الشريعة، أحكام، تأثير. Crossref doi) https://doi.org/10.51345/.v32i1.214.g198 
المقلدمة :

الحمد لله رب العالمين، و الصلاة والسلام على سيد المرسلين سيدنا محمد وعلى آله وصحبه اجعين. وبعد: فإن الله تعالى قد جمع في هذا الشرع من الاحكام والآداب ما يضمن له أن يكون خالداً باقياً، وصالحاً لكل زمان ومكان، مقدراً للأمة مصالحها، كافلاً لها ما يضمن ها السلامة ان تمسكت به، وحرصت عليه. ولا أدل على ذلك من مراعاتها في أحكامها لمصالح البشرية كلها، تلك المصالح التي قصدها الشارع الحكيم لعباده من حفظ دينهم، ونفوسهم ونسلهم ومالهم وعقولمم ودفع ما يضر بهذه الأصول أو يعطل تلك المصالح. ان دراسة المصالح المرسلة ها اهميتها ومكانتها، هذه الأهمية والمكانة تستمد من أهمية ومكانة المصالح المرسلة نفسها، وتستمد اهميتها ايضاً من تحديات العصر الحالي ومتطلباته وحو ادثه المختلفة . وقد تقرر نقلاً وعملاً قدياً وحديثاً ما للمصالح المرسلة من مكانة واهمية فعالة في فهم الاحكام والقيام بتكاليف وأداء الاحكام ورسم منهج الاجتهاد وتطبيقه على مستوى الافراد والشعوب والدول والامم والاحكام، وفي جميع جالات الحياة واحو الها وقضاياها ومطالبها، لأن هذه الشريعة مبنية على تحقيق مصالح العباد ودرء المفاسد عنهم في الدنيا والآخرة . وبناء على تأسيس القول ان المصالح المرسلة أصبحت وستظل مبحثاً شرعياً اسلامياً مهاً جداً، فقد دلت الاخبار والوقائع على كل هذا، والعصر النبوي قد شهد اقراراً للمصالح وعمل بها، وحفل عصر الصحابة والتابعين (رضي الله عنهم) باستعحال المصالح المرسلة توسيعاً وتعميقاً . وقد علم ان السياسة الشرعية هي فقه المصالح التي تقتضيها ظروف الأمة في كل زمان ومكان ، فان علماء

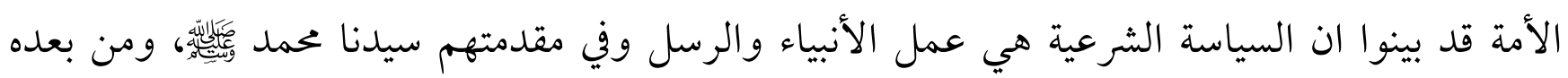
الصحابة الكرام والتابعون الأجلاء ومن سار على دربهم من الفقهاء. وبها ان قواعد السياسة الشرعية تعمل فيما فيه نص خاص وفيا لا نص فيه، والمصلحة المرسلة تعمل فيما لا نص فيه فهي بجال فسيح للنظر في احكام السياسة الشرعية والاجتهاد في مضانها لأجل بيان المصالح العامة 
التي يعمل بها أولي الأمر فاردت ان اجمع بين مضمون المصلحة المرسلة وعلم السياسة الشرعية فاخترت عنوان

$$
\text { البحث (المصلحة المرسلة وأثرها في السياسة الشرعية). }
$$

وأردت من خلال هذا العنو ان أن أبين احد مصادر الاستباط التبعية للتشريع الاسلامي وهو المصلحة المرسلة في صلاحيتها لمعالجة القضايا المستجدة، والذي يخرج من رحم الاجتهاد القائم على النظر الى مقاصد الشريعة، وهذا الأخير هو غاية علم السياسة الشرعية القائمة على المصلحة.

\section{المبـحث الاول: مفهوم المصلحة المرسلة والسياسة الشرعية$$
\text { المطلب الاول: المصلحة لغة واصطلاحًا : }
$$

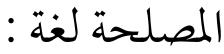

المصلحة: اسم مشتق من الفعل صلح يصلح وهي مادة تدل على أصلها اللغوي على ما هو نقيض الفساد، قال

ابن فارس: الصاد واللام والحاء: أصل واحد يدل على خلاف الفساد ويقال: صلح الشيء يصلح وصلاحاً(1). و الصلاح ضد الفساد: من صلح يصلح صلاحاً وصلوحاً ضد الافساد والمصلحة مصدر بمعنى الصلاح، والمصلحة واحدة المصالح، والاستصلاح نقيض الفساد، وأصلح الشيء بعد فساده : أقامه، ومن المجاز: أصلح اليه: أحسن (2).

جاء في أساس البلاغة: وصلح فلان بعد فساده، ورأى الامام المصلحة ونظر في مصالح المسلمين (3). والصلاح هو سلوك طريق الهدى وقيل : هو استقامة الحال على ما يدعو اليه العقل، والصالح: المستقيم الحال في نفسه (4)

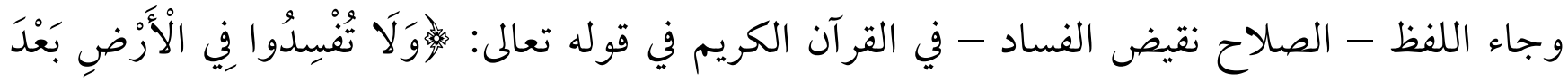

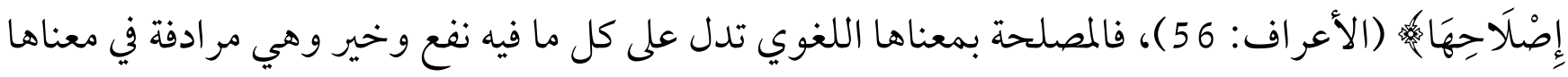

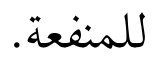

المصلحة اصطلاحاً: 
عرض الاصوليون لمعنى المصلحة في موضعين من كتبهم، فالأول عند الكلام على المناسب كمسلك من مسالك العلة في باب القياس، حيث عرفوه: "بأنه الوصف الظاهر المنضبط الذي يلزم من ترتيب الحكم على وفقه حصول ما يصلح ان يكون مقصودا من الشرع سواء أكان ذلك المقصود جلب مصلحة أو مفسدة"(5)، قال الشوكاني في مسلك المناسبة: "ويعبر عنها بالاخالة وبالمصلحة، وبالاستدر اك، وبرعاية المقاصد، ويسمى استخر اجها تخريج المناط، وهي عمدة كتاب القياس"(6). واما الموضع الثاني فعند الكلام على المصلحة كدليل عام، وهذا الموضع هو الذي يهمنا في هذا البحث، وها عدة تعريفات عند الاصوليين، نذكر منها: عرفها الامام الغزالي (ت 505 5ه): "المصلحة عبارة في الاصل عن جلب منفعة او دفع مضرة، ولسنا نبغي به ذلك فان جلب المنفعة ودفع المضرة مقاصد الخلق وصلاح الخلق في تحصيل مقاصدهم، لكنا نعني بالمصلحة المحافظة على مقصود الشرع ومقصود الشرع من الخلق خمسة، وهو أن يحفظ عليهم دينهم، ونفسهم، ونسلهم، ومالهم، وكل ما يفوت هذه الاصول فهو مفسدة ودفعها مصلحة، واذا اطلقنا المعنى المخيل او المناسب في كتاب القياس أردنا به هذا الجنس" (7). عرفها عز الدين بن عبد السلام (ت 606هـ) بقوله: "المصالح أربعة أنواع : اللذات وأسبابها، الأفراح وأسبابها، والمفاسد اربعة انواع: الآلام وأسبابها والغموم وأسبابها وهي منقسمة الى دنيوية وأخروية، فأما لذات الدنيا واسبابها وافراحها واسبابها فمعلومة بالعادات، وأما لذات الآخرة وأسبابها وأفراحها وأسبابها فقد دل الوعد والوعيد و الزجر والتهديد"(8). عرفها الشاطبي (ت 790هـ) بقوله: "وأعني بالمصالح ما يرجع الى قيام حياة الانسان وتمام عيشه ونيله ما تقتضيه أو صافه الشهو انية والعقلية على الاطلاق حتى يكون منعجاً على الاطلاق"(9). وعرفها الطوفي (ت 716هـ) بقوله: "أما حدها بحسب العرف هي السبب المؤدي الى الصلاح والنفع كالتجارة تؤدي الى الربح وبحسب الشرع هي السبب المؤدي المى مقصود الشارع عبادة او عادة والعبادة هي ما يقصده الشارع بحقه، اما العادة فهي ما يقصده لنفع المخلوقين وانتظام أحو الهم"(10). 
وبناء على ما تقدم من تعريفات فان مفهوم المصلحة يكاد يكون متفقاً عليه - فأما حدها عرفاً - وهو ما يوافق المعنى اللغوي وأنها مطلق النفع حقيقة أم بجازاً.

ومن خلال التأمل في التعريف اللغوي والاصطلاحي للمصلحة نجد أن بينها عموم وخصوص ؛ حيث ان معنى المصلحة في الشرع أخص من معناه في اللغة، فالمصلحة في أصلها اللغوي عامة تشمل كل منفعة، أما في الشرع فإنها المنفعة بشرط محافظتها على مقاصد الشارع، فكل مصلحة في الشرع هي مصلحة في اللغة وليست كل مصلحة في اللغة مصلحة في الشرع.

\section{المطلب الثاني: مفهوم المصلحة المرسلة:}

نتطرق في هذا المطلب المى معنى المصلحة المرسلة باعتبارها لقباً بعد أن عرفنا معنى المصلحة لغة و واصطلاحاً

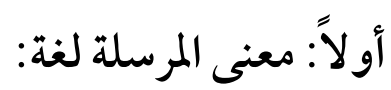

الارسال مصدر - ارسل - -وهو الاطلاق وعدم التقييد(11). يقال: ارسل الشيء أطلقه وأهمله، ويقال ارسل الكلام: أي اطلقه من غير تقييد، وارسل الرسول: بعثه برسالة) (12).

ويستعمل الفقهاء كلمة الارسال بإطلاقات متعددة(13). الارخاء: كإرسال اليدين في الصلاة . التوجيه: كإرسال شخص لآخر أو رسالة . التخلية: كإرسال المحرم ما تحت يده من صيد . الاهمال: كإرسال الماءو والنار و الحيوان . التسليط: كإرسال الحيو ان او السهم على الصيد . ويستعمل علماء الاصول معنى الارسال في المصلحة بنفس المعنى اللغوي السابق، أي المهملة او المطلقة من غير تقييد، ومن ثمة فان المعنى اللغوي والاصطلاحي للإرسال متطابقين كما سنبين ذلك . ثانياً: المصلحة المرسلة في الاصطلاح الثرعي: 
سنذكر بعض التعريفات لها :

عرفها الامام الغزالي بقوله: "كل مصلحة رجعت الم مقصود شرعي علم كونه مقصوداً بالكتاب والسنة والاجماع فليس خارجاً من هذه الاصول، ولكنه لا يسمى قياساً بل مصلحة مرسلة، إذ القياس من أصل معين وكون هذه المعاني مقصود عرف لا بدليل واحد بل بأدلة كثيرة لا حصر ها من الكتاب و السنة وقرائن الأحو ال وتفاريق الأمارات، فهي بذلك مصلحة مرسلة"(14). وعرفها الآمدي حين تعرض لأقسام المناسب فعبر عنها بالمناسب المرسل فقال: "هو الذي لم يشهد له أصل من أصول الشريعة بالاعتبار بطريق من الطرق المذكورة ولا ظهر إلغاؤه في صورة"(15). وعرفها تاج الدين السبكي (ت 771 هـ) بقوله: "هي التي لم يشهد لها من الشرع بالاعتبار أصل معين وإن كانت مما تتلقاه العقول بالقبول"(16). أما الشاطبي فقد عبر عنها بالاستدلال فقال: "المصالح المرسلة يرجع معناها المى اعتبار المناسب الذي لا يشهد له أصل معين، فليس له على هذا شاهد شرعي على الخصوص، ولا كونه قياساً بحيث اذا عرض على العقول تلقته بالقبول"(17)، ثم انه شرحها في كتابه الموافقات فقال: "هو أن كل أصل شرعي لم يشهد له نص معين، وكان ملائماً لتصرفات الشرع ومأخوذاً معناه من أدلته فهو صحيح يُبنى عليه ويرجع اليه اذا كان ذلك الاصل قد صار بمجموع أدلته مقطوعاً به، لأن الادلة لا يلزم أن تدل على القطع بالحهم بانفر ادها دون انضمام غيرها إليها، فإنه و إن لم يشهد للفرع أصل معين فقد شهد له أصل كلي"(18). ومن خلال التعاريف السابقة نلاحظ من ظاهرها انها متفقة ولكن مع بعض الخلاف، فمنهم من يراها انها ترجع الم حفظ مقصود من مقاصد الشرع في الجملة، ولها عدة ادلة او قرائن وامارات، وهذا يظهر من تعريف الامام الغزالي والشاطبي، اما الآمدي فانه يرى انها لم تشهد لها اصول الشريعة بالاعتبار، وبهذا فانه ينفي ان تكون المصلحة المرسلة قد شهدت لها اصول الشريعة الخاصة او العامة بالاعتبار، وقد صرح بذلك ابن الحاجب ايضاً( (19)، والزركشي (20)، اما السبكي فانه يرى انه لم تشهد لها الشريعة بأصل خاص ولكن تشهد ها النصوص و القو اعد العامة. 
والناظر لهم جميعاً فهم يرون ان العقول تلقتها بالقبول وها دليل على موافتتها لسنن المصالح العامة التي عُلمت شرعيتها باستقر اء مقاصد الشارع في كل الاحكام. وبناء على ما سبق يتبين لنا أن المصلحة المرسلة مصلحة خلت من الشواهد الخاصة، فاذا وقعت حادثة لم يُعلم

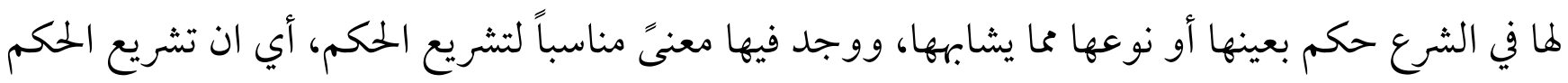

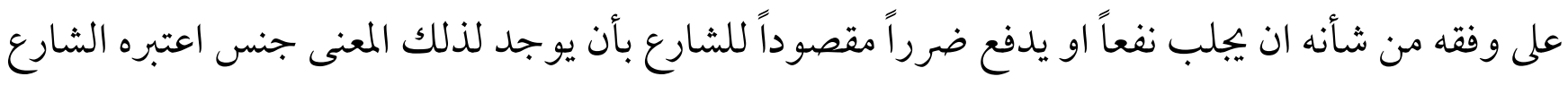
في جملة تصرفاته وملائم لمقاصده العامة فإنه صحيح يبني عليه ويرجع اليه كما قرر ذلك الشاطبي (21).

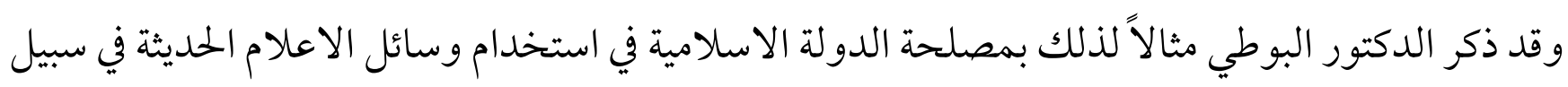
نشر الدعوة الاسلامية وتوفير الرفاهية لعامة المسلمين بالشكل الذي يتفق وضوابط الشريعة خاصة وأن هذه المصلحة اقتضتها الحياة المعاصرة المتطورة بين عشية وضحاها(22). فهذه مصلحة لم تشهل لها النصوص الخاصة ولكنها داخلة في قسم التحسينات من حيث توفير الراحة للناس، وقد تدخل في قسم المكمل الضروري اذا كانت تسخر في نشر تعاليم الاسلام وتبليغ دعوته (23).

\section{المطلب الثالث: أقسام المصلحة المرسلة:}

ان المتأمل في كتب الاصول لا يكاد يمد هناك من قسم المصلحة المرسلة بالقدر المفصل الا بعض الاشارات للإمام الغزالي، بقدر ما توسعوا في بيان أقسام المصلحة عامة، إلا ان هذا التقسيم الأخير يعتبر تقسيراً ثانياً للمصلحة المرسلة بطريق غير مباشر وقد اشار الى ذلك الشيخ ابن عاشور بعد ذكره لأنواع المصلحة بقوله:

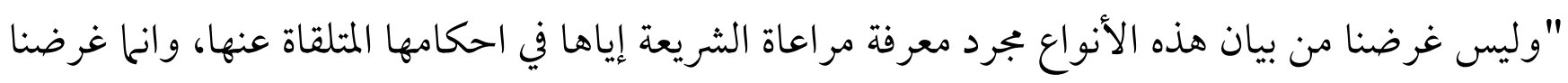

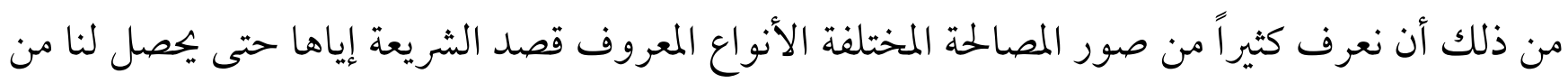
تلك المعرفة يقين بصور كلية من أنواع هذه المصالح، فمتى حلت الحوادث التي لم يسبق حلو لها في زمن الشارع ولا لها نظائر ذات أحكام متلقاة منه عرفنا كيف ندخلها تحت تلك الصور الكلية فثبت لما من الاحكام أمثال ما يثبت لكلياتها، وهذا ما يسمى بالمصالح المرسلة"(24)، فالحكم بالمصلحة المرسلة قد يكون في قسم

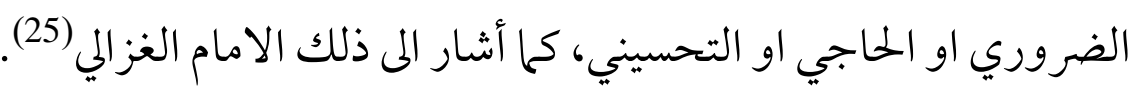


أولاً : اقسام المصلحة المرسلة باعتبار قوتها في ذاتها :

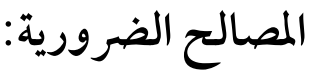

وهي التي لابد منها في قيام مصالح الدين والدنيا، بحيث اذا فقدت لم تجر مصالح الدنيا على استقامة بل على فساد وتهارج وفوت حياة، وفي الآخرة فوت النجاة والنعيم والرجوع بالخسر ان المبين (26). وفقدان هذا النوع من المصالح يؤدي الى اختلال نظام الحياة وعموم الفساد والفوضى في دنيا الناس، وانعدام النعيم في أخر اهم، وهذه الضروريات تنحصر في المحافظة على الدين، و النفس، والعقل، والنسل، والمال، وقد قرر العلماء أن حفظ الضروريات الخمس يكون بأمرين، أحدهما ما يقيم أركانها ويثبت قو اعدها، وذلك عبارة عن مراعاتها من جانب الوجود، والثاني ما يدرأ عنها الاختلال الواقع او المتوقع فيها، وذلك عبارة عن مراعاتها من جانب العدم(27)، ولأجل ذلك شرعت أحكام تحفظ كل واحدة من هذه الضروريات من

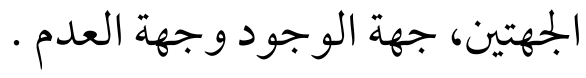
المصالح الحاجية: وقد عرفت: بأنها المصالح المفتقر إليها من حيث التوسعة ورفع الضيق المؤدي في الغالب الم الحرج والمشقة اللاحقة بفوت المطلوب، فاذا لم تراع دخل المكلفين الحرج والمشقة ولكنه لا يبلغ مبلغ الفساد العادي المتوقع في المصالح العامة(28). وقال ابن عاشور في تحديدها: "هو ما تحتاج الأمة اليه لاقتناء مصالحها وانتظام أمورها على وجه حسن بحيث لو لا مر اعاتها لا يفسد النظام العام ولكنه كان على حالة غير منتظمة فلذلك كان لا يبلغ مبلغ الضروري"(29). ومعنى ذلك ان تشريع الاحكام لحفظ مثل هذه المصالح لا يبلغ مبلغ الحفظ في أصل الضروريات بحيث اذا لم تشرع لم يحصل بفو اتها ما يحصل من فوات المصالح الضرورية من فساد واختلال لنظام الحياة، وانما يلحقهم الضيق والمشقة من ذلك، فجاء تشريعها توسعة عن الخلق ورفعاً للضيق والحرج عنهم · وقد مثل الاصوليون لهذه الانواع من المصالح بعدة أمثلة من العبادات والمعاملات والعادات والجنايات(30). 
فقي العبادات شرعت الرخص دفعاً للحرج، فأباح الشارع الجمع للمريض، وقصر الصلاة وجعها للمسافر، و التيمم عند فقد الماء وغيرها، وفي العادات كإباحة الصيد والتمتع بالطيبات مما هو حل مأكلاً ومشرباً وملبساً ومسكناً ومركباً، واما المعاملات شرعت انواع المعاملات المستثناة من القواعد العامة فأباح الشارع السلم والاستصناع والاجارات والمزارعة وما فيه حاجة للناس، وفي الجنايات شرعت الدية على العاقلة في القتل الخطأ تخفيفاً عن القاتل (31). فهذه الاحكام لا تصل الحاجة اليها المى حد الضرورة، الا ان الاستغناء عنها يوقع ضيقاً وحرجاً، وقد دلت

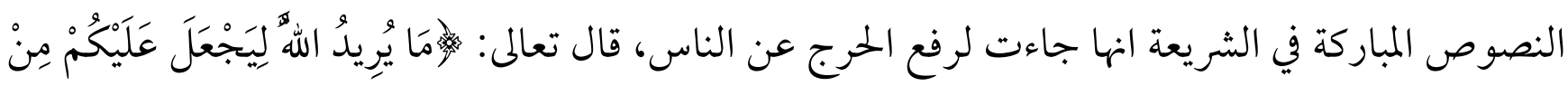

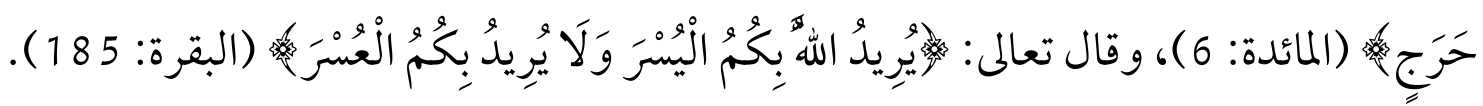
فالحكم بالمصلحة المرسلة منه ما يكون واقعاً في رتبة الحاجيات بأن يؤدي الحلكم الى رفع الحرج ومشقة زائدة على الناس، وقد قرر الامام الشاطبي أن حاصل المصالح المرسلة يرجع المى رفع حرج لازم في الدين(32)، اما الامام الغزالي فانه لا يرى الحكم بالمصلحة المرسلة الواقعة في هذه الرتبة الا ان تكون مصلحة شهد لها نص بالاعتبار حيث يقول: "و الواقع في الرتبتين الآخرتين - يقصد الرتبة الحاجيات والتحسينات - لا يجوز الحكم بمجرد ان لم يعتقد بشهادة اصل لأنه يجري بجرى وضع الشرع بالرأي، فهو كالاستحسان، وان اعتقد بأصل فذلك قياس"(33). ومعناها: "الاخذ بها يليق من محاسن العادات وتجنب الاحوال المدنسات التي تأنفها العقول الراجحات، ويجمع ذلك قسم مكارم الأخلاق"(34). وقد عبر عنها الامام الغزالي بقوله: "هي ما لا يرجع المى ضرورة ولا الى حاجة ولكن تقع موقع التحسين والتزيين للمز ايا ورعاية احسن المناهج في العادات والمعاملات"(35). 
فتشريع الاحكام رعاية لمثل هذه المصالح لا يقتضيه حفظ أصل ضروري ولا يحتاج اليه لرفع ضيق ومشقة زائدة بحيث تتحرج الحياة بتركها، ولكن جاء تشريعها من قبيل مر اعاة الفضائل الحسنة، واستكمال ما يليق من الاخلاق و التنزه عما يليق. وقد مثل لها الاصوليون بأمثلة في كل من العبادات والعادات والمعاملات والجنايات(36). يقول الشاطبي بعد ذكره الامثلة: "فهذه الأمور راجعة الى محاسن زائدة على أصل المصالح الضرورية والحاجية، إذ ليس فقدانها يمثل بأمر ضروري ولا حاجي وانها جرت بجرى التحسين والتزيين"(37). ثانياً: اقسام المصلحة المرسلة باعتبار العموم والخصوص: والمر اد بهذا التقسيم للمصلحة المرسلة هو معرفة مدى تعلق هذه المصلحة بجماعة الأمة أو بفرد من أفر ادها.

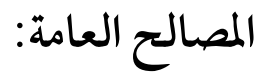
وقد اشار المى هذا التقسيم الشيخ الطاهر بن عاشور، حيث قال: "فتنقسم بهذا الاعتبار الى كلية وجزئية، وير اد بالكلية في اصطلاحهم ما كان عائداً على عموم الأمة عوداً ماثلاً، وما كان عائداً على جماعة عظيمة من الأمة أو قطر وبالجزئية ما عدا ذلك"(38). وقد عرفها بأنها: "هي ما فيه صلاح عموم الأمة او الجمهور، ولا التفات منه المى احوال الأفراد إلا من حيث أنهم أجزاء من بجموع الأمة، ومنه معظم فروض الكفايات كطلب العلم الديني والجهاد وطلب العلم الذي يكون سبياً في حصول قوة الأمة"(39). وقد أشار الامام الغزالي الى هذا النوع من المصالح المرسلة بالتمثيل له بمسألة القتل سياسة، كالساعي في الارض بالفساد(40)، سواء أكان يسعى بالدعوة الى البدعة اذا غلب على الظن ضرره وصار ذلك الضرر كلياً، أو بأكل أمو ال الناس وسفك دمائهم بإثارة الفتن بين المسلمين فالمصلحة قتله لكف شره عن الخلق. المصالح الخاصة: - (1) وتسمى ايضاً المصلحة الجزئية وهي مصلحة الفرد او الأفراد القليلة، وقد عرفها ابن عاشور بقوله: "هي ما فيه الآحاد باعتبار صدور الأفعال من آحادهم ليحصل بإصلاحهم صلاح المجتمع المركب منهم، فالالتفات فيه 
ابتداء المى الأفراد، وأما العموم فحاصل تبعاً، وهذا مثل حفظ المال من السرف بالحجر على السفيه مدة سفهه، فلذلك تقع لصاحب المال ليجده عند رشده، او يجده وارثه من بعده وليس نفعاً للجمهور "(41). ويمكن التمثيل للمصلحة المرسلة الخاصة بجواز قطع اليد أو الرجل للاككلة حفظاً للروح، فهذه المصلحة خاصة بشخص معين حفظاً لنفسه من الهلاك (42). وقد اشار الامام الغزالي الى هذا النوع للمصلحة المرسلة بمسألة فسخ النكاح لرفع الضرر عن امرأة المفقود(43)، فان في بقائها على عصمة زوجها المفقود الذي لم يعلم خبر موته او حياته ضرد بها من جهة بقائها بلا زوج ينفق وير اعي شؤونها، فني فسخ هذا النكاح دفع للضرر عنها ورعاية لجانبها بحلها للزواج. وقد روى الامام مالك في الموطأ عن سعيد بن المسيب ان عمر بن الخطاب هال: "أيها امر أة فقدت زوجها فلم تدر أين هو، فإنها تنتظر أربع سنين ثم تعتد أربعة اشهر وعشراً ثم تحل"(44)، وبهذا يقول الامام مالك: "يضرب لامر أته أجل أربع سنين من يوم أن ترفع أمرها الى الحاكم، فإذا انتهى الكشف عن حياته أو موته فجهل ذلك ضرب لها الحاكم الأجل، فاذا انتهى اعتدت عدة الوفاة أربعة اشهر وعشراً وحلت"(45). وهذا الحكم مبناه على تحرير النظر بحسب الاصلح في الشرع وهو الذي يعرف بالقياس المرسل (46)، وهي مصلحة نادرة تتعلق بشخص واحد في حالة نادرة.

\section{المطلب الرابع: مفهوم بالسياسـة الشرعية لغة واصطلاحًا :}

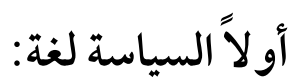

مشتقة من مادة (س و س) (7 4 )، وقد وضع لهذه المادة معان متعددة ومختلفة، لكن الذي يهمنا هنا هو ما يدل على الرياسة والتدبير والاصلاح. فالسَّوْس الرياسة، يقال ساسوهم سوساً إذا قادهم وترأسوا عليهم، واذا رأسوه قيل : سوسوه وأساسوه، وساس الأمر سياسة : قام به، وسوسه القوم: جعلوه يسوسهم، ويقال: سُوِّس فلان أمرين فلان: أي كلف سياستهم. وفي الحديث الشريف: "كانت بين اسرائيل تسوسهم الانبياء"(48)، أي تتولى أمورهم كما يفعل الأمراء والو لاة بالرعية. فالسياسة : القيام بالشيء بها يصلحه . 
وهذا المعنى الاخير قوي الصلة بالمعنى الشرعي للسياسة، ذلك أن الامام يقوم على اصلاح شؤون الامة وتدبيرها بما يصلحها وينفعها في دنياها وأخر اها(49). الشرعية لغة: مأخوذة من لفظ (شرع)(50)، بمعنى سن ويسن، والشريعة والشراع والمشرعة: المواضع التي ينحدر الم الماء منها، وبها سمي ما شرع الله لعباده من الصوم و الصلاة والحج و النكاح وغيره(51). و التشريع: ايراد الابل شريعة لا يحتاج معها المى نزع بالعلف ولا سقي في الحوض، وهو سن القو انين أيضاً(52)، وشرع الدين: سنه وبينه، والشريعة والشرعة: ما سن الله من الدين وأمر به كالصوم والصلاة والحجج والزكاة

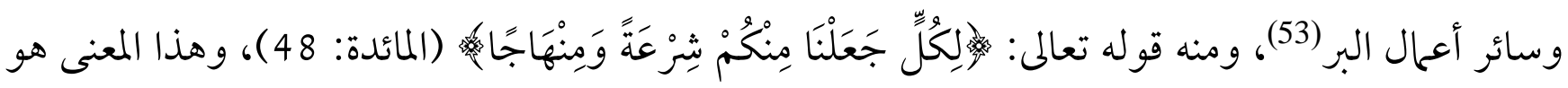
المقصود، والذي لا يخرج عن المعنى الشرعي. ثانياً: السياسة الشرعية اصطلاحاً: عرفت السياسة الشرعية بتعريفات عدة للفقهاء قدياً وحديثاً ومنها: "فعل شيء من الحكم بمصلحة ير اها، وان لم يرد بذلك الفعل دليل جزئي"(54). "استصلاح الخلق بإرشادهم الى الطريق المنجي في الدنيا والآخرة"(55). "السياسة حياطة الرعية بلا يصلحها لطفاً وعنفاً"(56). "السياسة اصلاح أمور الرعية وتدبير أمورهم"(57). وعرفها ابن عقيل فيا نقله ابن القيم: "السياسة ما كان فعلاً يكون معه الناس أقرب الى الصلاح وابعد عن الفساد، وان لم يضعه الرسول ولانزل به وحي" (58). اما العلم|ء المعاصرون فنذكر تعريفاتهم:

"تدبير الأمر في الأمة داخلاً وخار جاً تدبيراً منوطاً بالمصلحة"(59)، او القيام على الشيء بما يصلحه"(60). "تدبير الشؤون العامة للدولة الاسلامية بها يكفل تحقيق المصالح، ودفع المضار مما لا يتعدى حدود الشريعة و أصو لها الكلية وان لم يتفق واقو ال الأئمة المجتهلين"(61). 
"هي الاحكام الشرعية التي تنظم بها مرافق الدولة وتدبير شؤون الأمة، مع مراعاة أن تكون متفقة مع روح الشريعة، نازلة على اصولها الكلية، محقة اغراضها الاجتحاعية، ولو لم يدل عليها شيء من النصوص الجزئية الواردة في الكتاب و السنة"(62).

كل التعاريف جاءت على نحو عام، والناظر فيها يجدها عامة كقولهم (الخلق) و(الرعية) و(الناس). فتكون بذلك السياسة الشرعية غير قاصرة على فئة دون فئة او طائفة دون طائفة، وهذا يجعلها تسعى من أجل مصلحة الناس من غير تمييز عرقي أو ديني او قومي.

\section{المبـحث الثاني: حجية المصالح المرسلة وضوابط العهمل بها وعلاقتها بالسياسة الشرعية} المطلب الاول : حجية المصلحة المرسلة (63): : اختلف العلم) في اعتبار المصلحة المرسلة على مذاهب: الاول: منع التمسك بها مطلقاً واليه ذهب القاضي أبو بكر الباقلاني وابن الحاجب من المالكية وطوائف من المتكلمين (64)، وبه قال الآمدي، حيث قال: "و المصالح المرسلة وان غلبت على الظن لا ييوز العمل بها"(65). وقال ان هذا الرأي متفق عليه عند الشافعية والحنفية فقال: "اتفق الفقهاء من الشافعية والحنفية وغيرهم على امتناع التمسك بالمصلحة المرسلة وهو الحق" (66)، ولكن الحق ان مذهب الشافعي غير ذلك وانها هذا لبعض

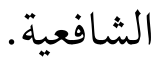

الثاني: قال بالجواز مطلقاً وهو المحكى عن الامام مالك(67)، واحمد(68)، وقال عبدالوهاب خلاف بأن هذا الر أي للجمهور مؤكداً بأن المصلحة المرسلة حجة شرعية يبنى عليها تشريع الاحكام(69). الثالث: انها حجة بشرط ملائمتها للمصالح المعتبرة، وهذا ما نسبه امام الحرمين للشافعي ومعظم اصحاب ابي حنيفة، قال امام الحرمين: "ذهب الشافعي ومعظم اصحاب ابي حنيفة الم تعليق الاحكام بالمصالح المرسلة شرط الملائمة للمصالح المعتبرة فالشافعي تمسك وان لم يستند الى اصل على شرط قربه من معاني الاصول الثابتة"(70). 
الرابع: ان كانت تلك المصلحة ضرورية قطعية كلية كانت معتبرة فإن فقد أحد هذه الثلاثة لم تعتبر، والمراد بالضرورية أن تكون من الضروريات الخمس (الدين، النفس، العقل، النسل، المال) والمراد بالكلية التي تعم جميع المسلمين وليس لبعض الناس دون بعض أو في حالة مخصوصة دون حالة واختار هذا البيضاوي(71)، والغزالي ومثل للمصلحة المستجمعة بمسألة الترس. ومن خلال عرض اقوال المذاهب تبين انه ليس هناك اتفاق بين فقهاء الشافعية والحنفية على منع التمسك بالمصلحة المرسلة مطلقاً كما ذكر الآمدي فبدا واضحاً من كلام امام الحرمين ان مذهب الامام الشافعي غير ذلك، هذا بالإضافة المى أن الغزالي وهو من الشافعية لم يمنع من التمسك بالمصلحة المرسلة مطلقاً وإن كان ضيق في الشروط لقبو هلا. وبعد النظر والتأمل في مذاهب العلماء في صلاحية المصلحة المرسلة للاستدلال نجد انه يمكن حصر هذه

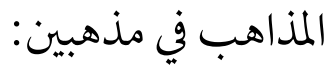
الاول: مذهب القائلين باعتبار المصلحة المرسلة صالحة للاستدلال بها. الثاني: مذهب القائلين بعدم اعتبار المصلحة المرسلة صالحة للاستدلال بها. اما ادلة القائلين باعتبار المصلحة المرسلة صالحة للاستدلال بها: فقد استدلوا بالقر آن والاجماع والمعقول.

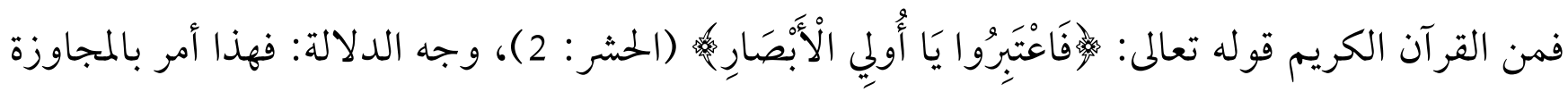
والاستدلال بكونه مصلحة على كونه مشروعاً بجاوزة فوجب دخوله تحت النص (72).

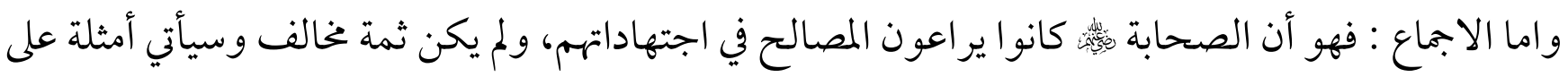
ذلك ان شاء الله، لعلمهم بأن المقصد من الشريعة رعاية مصالح الناس فعلم أن هناك ابماع عندهم على جواز التمسك بالمصلحة (73). 
قال الشاطبي: "وان كان البناء على المصالح المرسلة غير صحيح عند جماعة فالحجة عليهم اجماع الصحابة على

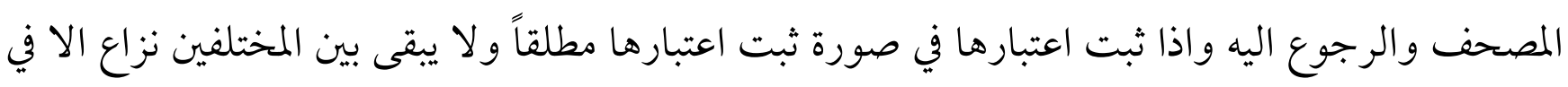

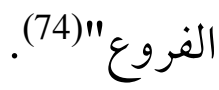
اما الشافعي فقد قال: "انا نعلم قطعاً أن لا تخلو واقعة عن حكم الله تعالى فالأئمة السابقين ومن قبلهم

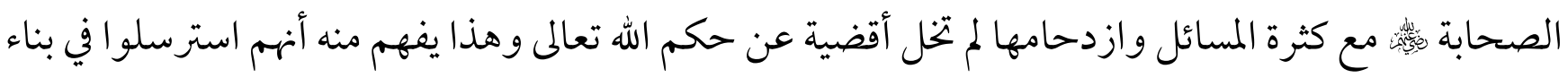

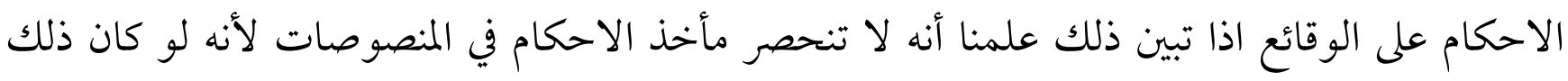
كذلك لما اتسع باب الاجتهاد والمنصوصات لا تقع من متسع الشريعة غرفة من بحر ومما قاله الشافعي اذا استندت المعاني المى الاصول فالتمسك بها جائز "(75). اما من المعقول فمن وجهين: - المين الاول : أننا اذا قطعنا بأن المصلحة الغالبة على المفسدة معتبرة قطعاً عند الشرع ثم غلب على ظننا أن هذا الحكمم

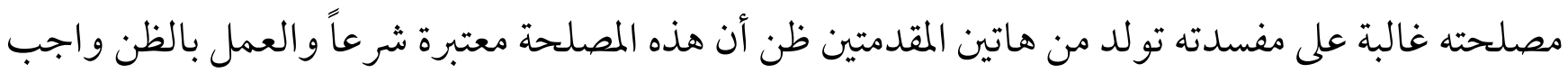

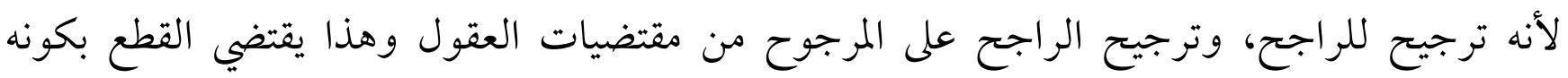
حجة (76).

الثاني: لو لم تكن المصلحة المرسلة حجة لأفضى ذلك الى خلو كثير من الوقائع عن الاحكام الشرعية، فمصالح

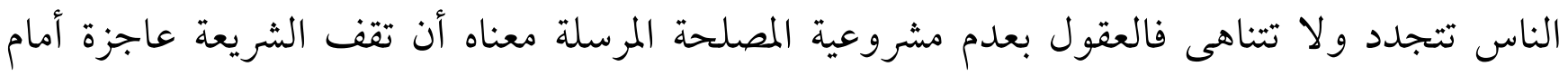
تطورات الناس ومصالحهم، وهذا لا يتفق مع مقاصد الشريعة (77). اما ادلة القائلين بعدم اعتبار المصلحة المرسلة صالحة للاستدلال بها: اولاً: ان الشريعة راعت كل مصالح الناس بنصوصها عن طريق سبلها الاربعة الكتاب والسنة والاجماع ويها ارشدت اليه من القياس، فالشرع جاء كاملاً فيه تبيان كل شيء وقرروا ان سائر مصالح المسلمين موجودة في

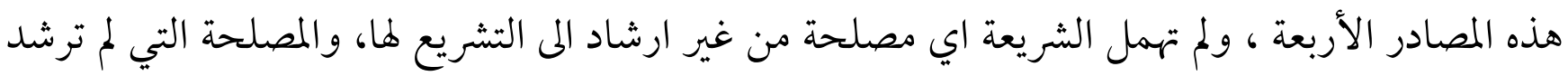
اليها الشريعة ليست في الحقيقة مصلحة (78). 
الثاني: التشريع بناء على المصلحة فيه فتح لباب الهوى، فبعض الناس قد يتخيل المفاسد مصالح، سيا وأن المصلحة أمر نسبي تحتلف باختلاف الناس وبيئاتهم، ففتح باب التشريع لمطلق المصلحة فتح لباب الشر (79)، فالمعاني اذا كانت محصورة بالأصول مضبوطة بالنصوص تكون منحصرة في ضبط الشارع، اما اذا لم تكن كذلك فانه يتسع أمرها ويصير ذوو الاحلام بمثابة الانبياء ويصير ما يقولونه كأنه الشريعة وهذا ذريعة في الحقيقة المى ابطال أبهة الشريعة، وهذا يعني أن كلاً سيفعل ما يراه مناسباً وأن ذلك سيختلف اختلاف الزمان والمكان وأضاف الخلق وهو في الحقيقة خروج عما درج عليه الاولون(80). ثالثاً: احتجوا بأن الكتاب والسنة متلقيان بالقبول والاجماع ملتحق بها و القياس المستند بالإجماع هو الذي يعتمد حكماً و أصله متفق عليه أما المصلحة المرسلة، فقسم لا يشهد له أصل من الأصول الثلاثة وانتفاء الدليل على العمل بالمصلحة المرسلة دليل انتفاء العمل بها(81). وقد رد عليهم اصحاب المذهب الاول بأن الزمان يتغير وتبدو في كل عصر مصالح جديدة لم يكن يراها الأولون فلو لم يشرع الاستصلاح لتعطلت مصالح كثيرة للعباد وان القول بتحريم المصلحة ليس أهون من القول بإباحتها فكلاهما نوع من الرأي لا نص فيه(82). تحرير النزاع والر أي الراجح: يتفق جمهور الفقهاء على ان المصلحة معتبرة في الفقه الاسلامي، وأن كل مصلحة يجب الأخذ بها ما دامت ليست شهوة ولا هوى(83)، والمصلحة ان نظر اليها من حيث لذة موافقة بهوى النفس، فبهذا الاعتبار فالجميع متفق على ردها وعدم اعتبارها، أو ينظر اليها من حيث تقام الحياة الدنيا للحياة الأخرى فهذا الذي وقع فيه النزاع بين العلم)ء(84). وقد بينا اقسام المصلحة المرسلة من قبل باعتبار الشرع لها(85). وبعد هذا الكلام وآراء العلم)ء يتبين لنا ان العلم)ء الذين احتجو ا بالمصالح المرسلة ترجح لرأيه على المانعين ها لأمور منها: ان مصالح تتجدد وفي كل يوم تظهر مصلحة لم تكن معروفة من قبل فلو لم نقل بكون المصلحة المرسلة حجة وأن المصالح المعتبرة هي فقط المصالح التي اعتبرها الشارع بنص او اجماع فهذا معناه تعطيل لكثير من مصالح 


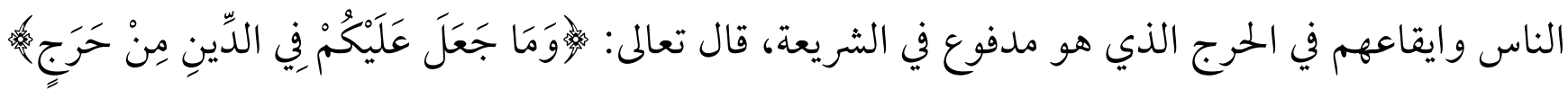

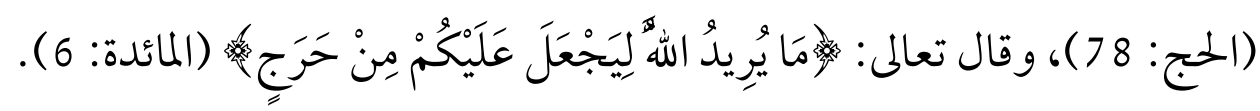

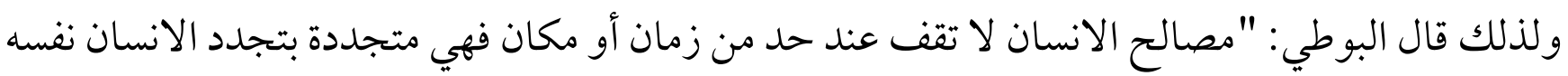
كان لابد من التطلع الى المصلحة المرسلة دفعاً للحرج الذي قد يتطرق للإنسان عند عدم الأخذ بها الأمر الذي

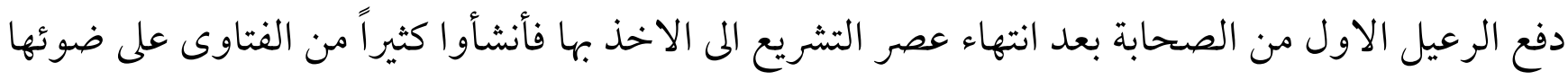
وتلقفها من بعدهم التابعون، ثم التزمها بعد ذلك أئمة المذاهب، ولست أرى أرى لهذا التعاقب من معنى إلا انهم متفقون على اعتبارها ولا يضير هذا الاتفاق ان ينكر القول به آحاد الاصوليين كما لا يضيره اختلاف الأئمة فيما بينهم في كثير من جزئيات الاحكام مع اتفاقهم عن الأخذ بمدركها كاختلافهم في كثير من المسائل المدلول عليها بالقياس مع اتفاقهم على الاخذ به واعتبار مدركه" (86). انه من استقرأ تشريع الصحابة والتابعين والأئمة المجتهدين تبين انهم شرعوا احكاماً كثيرة لتحقيق مطلق المصلحة (87).

\section{المطلب الثاني: ضوابط وشروط العمل بالمصالح المرسلة:}

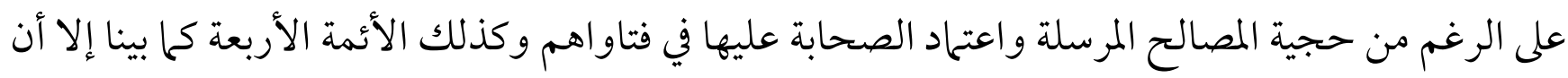
القائلين بالمصلحة المرسلة احتاطوا للاحتجاج بها حتى لا تكون باباً للهوى ولهذا قال الاستاذ خلاف:

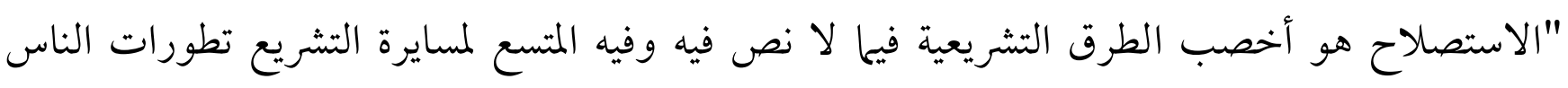
وتحقيق مصالحهم وحاجاتهم والتشريع به يجتاج الى مزيد من الاحتياط في توخي المصلحة وشدة الحذر من

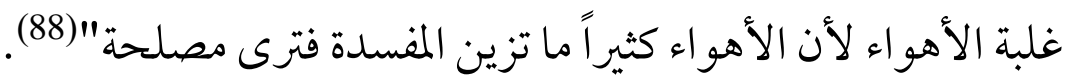
وقال ابن دقيق العيد: "لست أنكر على من اعتبر أصل المصالح لكن الاسترسال فيها يحتاج الى نظر

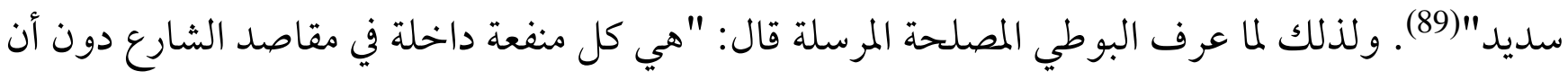
يكون لها شاهد بالاعتبار أو الالغاء"(90). 
فهذا يعني أن المصالح المرسلة وإن لم يكن هناك نص عليها بعينها إلا أنها حتى تكون صحيحة ويحتج بها لابد وأن تكون في اطار مقاصد الشريعة أي أن الشرع اعتبر جنسها البعيد ولهذا سأضع بين يدي القارئ في هذا المطلب بعضاً من ضو ابط المصلحة المرسلة كما بينها القائلون بها حتى لا تزل الاقدام ولا تضل الأفهام. الشرط الاول: ان ترجع الى قصد الشارع وتكون موائمة وملائمة له، وذلك بأن يكون فيها حفظ لمقصد من مقاصد الأصول الخمسة، لا أن ترجع الى مقصد المكلف المجرد الذي لا يستبعد أن يناقض قصد الشارع من التشريع ويهدم الشريعة من أسبابها، ويقصد بهذا الضابط أيضاً أن لا تعود المصالح المتخذة على المقاصد الشرعية بالإبطال والازالة او بالإخلال والتحجيم (91). الشرط الثاني: عدم معارضة المصلحة المرسلة للأحكام التفصيلية الثابتة في الكتاب أو السنة أو الاجماع أو القياس (92)، قال ابو زهرة: "إن المصلحة ثابتة حيث وجد النص فلا يمكن أن تكون هناك مصلحة مؤكدة او غالبة والنص القاطع يعارضها إنها هي ضلال الفكر أو نزهة الهوى أو غلبة الشهوة"(93)، فمثلاً "لا يصح اعتبار المصلحة التي تقتضي مساواة الابن والبنت في الإرث لان هذه مصلحة ملغاة لمعارضتها نص

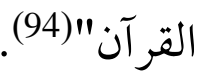
الشرط الثالث: أن تكون مصلحة حقيقية بمعنى أنه لابد أن يجلب بها نفع أو يدفع بها ضرر وأما اذا كانت وهمية فلا يصح بناء الاحكام عليها، ومثال المصلحة الوهمية سلب الزوج الحقى في تطليق زوجته، وجعل هذا من حق القاضي في جميع الحالات(95). الشرط الر ابع: أن تكون مصلحة عامة تجلب النفع لأكبر عدد من الناس أو تدفع الضرر عنهم فلا يشرع حكم لكونه يجقق مصلحة خاصة فالعبرة بمجموع الأمة أو الأكثرية الغالبة ولا عبرة بالمصالح الفردية(96). الشرط الخامس: ألا يفوت العمل بها مصلحة أهم منها أو مساوية لها. ان المقاصد خمسة (الدين والنفس والعقل والنسل والمال) وهي مرتبة من حيث الأهمية كما ذكرت وفي حال التعارض مصلحة الدين مقدمة على مصلحة النفس وهكذا، فعلى سبيل المثال الجهاد مع أنه قد يؤدي الى اتلاف النفس إلا أن هذا لا يلتفت اليه لما في الجهاد من حفظ مصلحة الدين الذي هو أهم منها، كذلك مراتب 
المصالح ثلاث (ضروريات وحاجيات وتحسينات) و الضروري مقدم على الحاجي عند التعارض وهكذا، فعلى سبيل المثال يباح كشف العورة امام الطبيب لضرورة العلاج مع العلم ان سترها امر تحسيني وذلك لأن الضروري مقدم على التحسيني عند التعارض (97).

\section{المطلب الثالث: علاقة المصلحة المرسلة بالسياسة الشرعية:}

اذا اردنا ان نتحدث عن قيمة ووزن المصالح المرسلة كدليل استنباطي تبعي بالنسبة للسياسة الشرعية، فيمكننا أن نقول: ان هذه القيمة تتضح معالمها من خلال استقرائنا لأقو ال العلماء في ذلك. ولذلك فان المحرك الاساس لتغير الاحكام هو نظرية الاستصلاح، فلا يكون اعتبار الأزمنة والأمكنة والعوائد والأعراف إلا لتحصيل مصالح العباد ودفع المفاسد عنهم، فكل هذه الأمور والأسباب تدور حول تحقيق مقاصد الشريعة من جلب المصلحة للعبد ودفع المفسدة عنه، وهذا مما يؤكد لنا من أن تغير الحكم قائم على المصلحة المرسلة بشكل أساس. ان الاجتهاد في مسائل السياسة الشرعية قد يؤدي الم استباط أحكام اجتهادية سابقة إذا ما أصبحت غير محصلة لمصلحة أو مؤدية لضرر أو فساد، أو غير مسايرة لتطور الأزمان والأحوال والأعراف، أو كانت الأحكام الاجتهادية الجديدة اكثر تحقيقاً للمصالح ودفعاً للمفاسد، ومن ثم يمكننا أن نحدد العلاقة بينها، وذلك كما يأتي: يرى الشيخ خلاف ان السياسة الشرعية هي العمل بالمصالح المرسلة فقط وهذا ما بينه فقال: "فالفقهاء أرادوا بالسياسة الشرعية التوسعة على ولاة الأمر في أن يعملوا ما تقضي به المصلحة مما لا يخالف أصول الدين وان لم يقم عليه دليل خاص" (98). وقال ابن نجيم في حد الزنا: "وظاهر كلامهم ههنا أن السياسة هي فعل شيء من الحكم لمصلحة يراها وإن لم يرد بذلك الفعل دليل جزئي "(99). فالسياسة الشرعية على هذا هي العمل بالمصالح المرسلة؛ لأن المصلحة المرسلة هي التي لميقم من الشارع دليل على اعتبارها او الغائها. 
ذهب العديد من الفقهاء المى ان السياسة الشرعية هي ثمرة الاجتهاد الاستصلاحي، ويؤيد هذه الوجهة العلماء

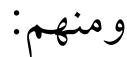
يقول الدريني: "السياسة الشرعية ثمرة الاجتهاد بالرأي فيا لا نص فيه" ويقول ايضاً: "هذا المنهج الفذ من الاجتهاد بالرأي في التشريع الاسلامي خليق أن يضمن استمرار حياة هذا التشريع ونفاذه وآثاره، مها تطورت بالناس الظروف، ومها اعتبر من وقائع واحداث نتيجة للتقدم العلمي وارتقاء مفاهيم الخضارة")(100).

ويقول: "فسياسة التشريع إذن تقوم أساساً على فقه المصالح فيها لا نص فيه"(101). ومعلوم أن أخصب الطرق التشريعية فيما لا نص فيه هو دليل المصالح المرسلة، ففيها المتسع لمسايرة التشريع الاسلامي لتطورات الناس، وتحقيق مصالحهم وحاجاتهم. ويقول الزرقاء أيضاً: "الاحكام التي تبنى على قاعدة المصلحة المرسلة يمكن تصنيفها الى نوعين: النوع الاول: الاحكام التي تتعلق بشؤون الادارة العامة المنظمة لمصالح المجتمع، وهي التدابير التي يتوقف عليها تنظيم تلك الشؤون والمصالح العامة، وذلك كفرض الضرائب على المقتدرين عند الحاجة الى الأعحال كتجهيز الجيوش، وبناء الجمسو، وتخطيط الأراضي وإحصاء النفوس، وتعبيد الطرق، وانشاء المستشفيات ودور العجزة، وسائر وجوه الضمان الاجتماعي الذي ينفي البؤس، ويكفل العمل لمن يريده ويكقق لجميع الناس المستوى اللائق في المعيشة والمر افت الضرورية لحياتهم، ومن هذا القبيل أيضاً ما أحدثه عمر بن الخطاب

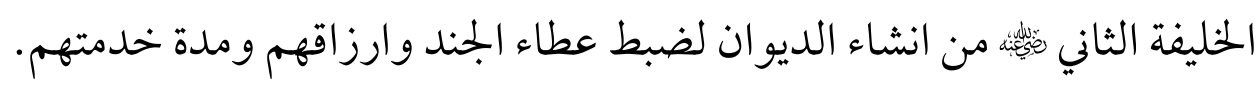
وكل ذلك هو مقتضى الو لاية العامة لصاحب السلطة العليا في الدولة من خليفة أو غيره. النوع الثاني: الاحكام التي تتعلق بالنظام القضائي و الحقوق الخاصة"(102). ويقول القرافي: "ان التوسعة على الحكام في الاحكام السياسية ليس خخالفاً للشرع، بل تشهد له الأدلة، وتشهد له القو اعد، ومن أهمها كثرة الفساد وانتشاره والمصلحة المرسلة التي قال بها مالك وجمع من العلم)"(103). 
ويقول الخادمي: "الظنيات التي تقبل الاجتهاد الاجتماعي المقاصدي(104)، وذكر منها: كيفيات بعض المعاملات ومثال ذلك تفاصيل تطبيق الشورى والعدل وكيفيات الأمر بالمعروف والنهي عن المنكر "(105). والتصرفات السياسية هي جملة التصرفات التي أوكلها الشارع أولي الأمر من الساسة والحكام والعلماء كي يحددونها على وفق المصالح الشرعية، وذلك على نحو: اعداد خطط التنمية وسياسات التعليم والاعلام، وتنظيم الهياكل والنظم الادارية والمالية والقضائية، وضمان الأمن، وزجر البغاة، وصد المعتدين، وتقوية الجيوش، وانشاء الحروب، وابرام المصالحات والمعاهدات والاتفاقيات، وغير ذلك ما يراه اهل السياسة الحكماء بمصالح الدولة، والخبراء بقواعد الشريعة ومقاصدها المقررة ... مما يتعين ضرورته حسب ضوابط الدين، وشروط الاجتهاد، وقو اعد الاستصلاح المقرر"(106). وبهذا فهو يبين ان هذه التصرفات السياسية والتي تأتي في سياق احكام السياسة الشرعية تقوم على قواعد الاستصلاح الشرعي.

ان السياسة الشرعية هي المجال الأمثل والرحب الذي يضفي الطابع العملي أو التطبيقي على المفهوم الأصولي للمصلحة، وهذا الفقه السياسي في تصريف شؤون الحكم في الدولة، ووجوه التدبير فيها عملاً يقوم معظمه على المصالح المرسلة التي تثبت اعتبارها بدليل اجمالي لا تفصيلي. وهذا ما أكده الدريني فقال: "فأساس سياسة التشريع إذن، فضلاً عن الأدلة التفصيلية، الأدلة الاجمالية، وفي مقدمتها المصالح المرسلة وسد الذرائع "(107). وعليه فان السياسة الشرعية أو الفقه السياسي، هو فقه المصالح المرسلة، فالمصالح المرسلة ها عظيم الأثر وقوي العلاقة بأحكام السياسة الشرعية.

المبحث الثالث: أثر المصلحة المرسلة ِِِ السياسلة الشرعية 
ما لا شك فيه أن المصالح المرسلة باعتبارها تناط بتحقيق مقاصد الشريعة، وهي في الوقت نفسه لا دليل على اعتبارها ولا الغائها، لذلك فهي قادرة على إنشاء الأحكام الشرعية لكل ما يجد من الوقائع والاحداث في كل زمان ومكان، وهذا يبرز بجلاء مرونة وو اقعية الشريعة الاسلامية. كذلك فان العرف يمكن أن يكون مساعداً للتشريع، بمعنى أنه يقدر على انشاء تغيير أحكام شرعية، وهو في النهاية راجع الى نظرية الاستصلاح، فلا يتعارف الناس في بيئاتهم وأزمانهم إلا على ما فيه مصلحتهم وتحقيق حاجاتهم. وسنركز هنا على أثر المصلحة المرسلة في احكام السياسة الشرعية في كل العصور.

المطلب الأول: أثر المصلحة المرسلة يِّ أحكام السياسلة الشرعية فِف عصر الصحابة: ان من يتتبع اجتهادات الصحابة (رضي الله عنهم) يجد أنهم لم يكونوا يتو انون لحظة عن ترتيب الاحكام وفق المصالح، متى لمسو ا فيها الخير ووجدوا أنها مندرجة ضمن مقاصد الشريعة. ولقد كان لاتساع الدولة الاسلامية في عهدهم أثر كبير في إبراز هذه الحقيقة لديهم، فقد وضعتهم ظروفهم أمام مصالح كثيرة نختلفة لم يكن شيء منها على عهده منصوص عليه، فيقيسونه عليه، ويعمدون الى ما لم يتو فر من حوله شبيه له، فيتخذون الأداة التشريعية المحققة لما فيه من مصالح، ما دام أنها لا تتعارض مع أي نص لكتاب أو سنة. والأمثلة على ذلك كثيرة منها: عهد أبي بكر لعمر (رضي الله عنها) بالخلافة:

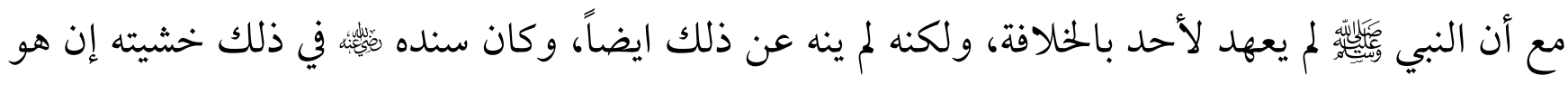
قبض ولم يعهد بالخلافة لأحد بجمع شتات المسلمين ويو حد كلمتهم أن يعود الاختلاف بينهم بأخطر مما ظهر بينهم بعد انتقال النبي وَّيَّلَّة الى الرفيق الاعلى، وفي ذلك ما يجعل للعدو مطمعاً فيهم، فكانت مصلحة الحيطة في حفظ وحدة المسلمين وحماية شو كتهم، وهي بلا شك داخلة في مقاصد الشارع وان لم يرد بذلك نص أو دليل معين (108). 
عقوبة شارب الخمر : - مقاب

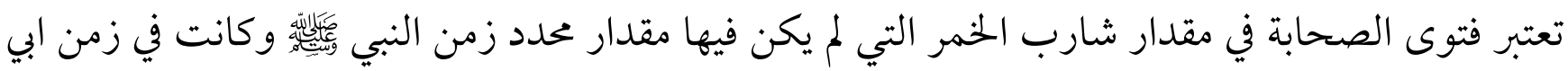

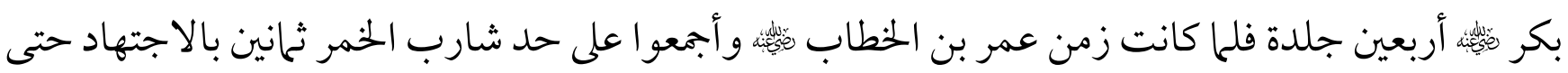
قال علي بن أبي طالب نِّئه: إنه اذا شرب سكر واذا سكر هذى واذا هذى افترى فأرى ان يقام عليه حد المفتري، وقال عبد الرحمن بن عوف هذا حد واقل الحدود ثمانون(109). فكانت المصلحة المرسلة من تغيير عقوبة شارب الخمر هي انه لما رأوا الصحابة تزايد الاقدام على شرب الخمر وتهاون الناس في ذلك، لأن العقوبة لم تكن رادعة فقد اجمع الصحابة في زمن عمر مِئئ، على جعل حد شارب الخمر ثلانين جلدة لتكون زاجرة ورادعة لشاربين الخمر لتحقيق مقصود الشارع في فرض عقوبة شارب الخمر فكان زيادة مقدار الجلد تدبير سياسي من امير المؤمنين عمر بن الخطاب نِئئ. قتل الجماعة بالواحد: - مداع والمستند فيه المصلحة المرسلة اذ لا نص على عين المسألة ولكنه منقول عمر بن الخطاب ضِئزة، وهو مذهب الثوري والاوزاعي والليث ومالك وابو حنيفة والشافعي وأصحابهم واحمد واسحاق وابو ثور (110). ووجه المصلحة ان القتيل المعصوم وقد قتل عمداً فإهداره الم حزم أصل القصاص واتخاذ الاستعانة والاشتر اك ذريعة الى السعي بالقتل إذا علم انه لا قصاص فيه(111).

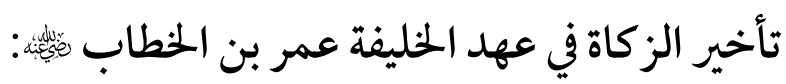
ويتجلى ذلك في انه فئيّة أخر الزكاة عن أرباب الماشية من الإبل والبقر والغنم في عام الجلدب على أن يأخذها منهم بعد أن تتحسن ظروفهم، وفي ذلك تقديراً لأمر مصلحي وهو التيسير على الناس في عام الجدب والقحط؟ ولم يلزم الخليفة الناس بدفع الزكاة الا بعد ان انتهت عام الرمادة إلا انتهت المجاعة وخصبت الأرض، بعد ذلك أمر في جمع الزكاة عام الرمادة ثم أخذها منهم بعد ان عدها ديناً في ذمة القادرين منهم حتى يسد العجز، لدى الأفر اد المحتاجين، وليبقى في بيت المال رصيداً بعد ان انفقه عليه على الناس (112). 


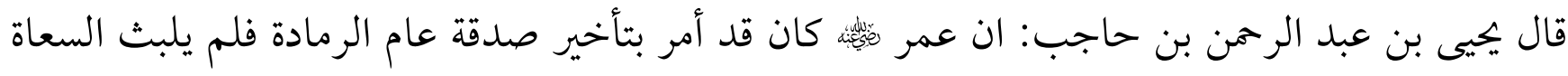
جامعي اموال الصدقات، فلم) كان عام قابل، ورفع الله ذلك الجدب، أمرهم ان يخرجوا عقالين، فأمرهم ان يقسموا عقالاً(113)، ويقوموا عليه بعقال، فما وجد في بني فزارة كلها الا ستين فريضة، فقسم ثلاثون، وقدم عليه الساعي بثلاثين الباقية(114). وهذا موقف فيه تدبير مصلحي قام به أمير المؤمنين عمر بن الخطاب ثِئئن بحكم ولايته على المسلمين فقد غير فيه الحكم أو أخر تطبيق الحكم الشرعي وهو اجتهاد مبني على المصلحة المرجوة من ذلك ورفع المشقة والحرج عن ارباب الاموال في ذلك العام لما لحقهم من قحط وجدب. حذف كلمة الجزية عن نصارى تغلب: قبل امير المؤمنين عمر بن الخطاب هِئن: من نصارى تغلب الجزية باسم الصدقة وضعفها عليهم وقال لهم: "سموها ما شئتم"(115). فكان هذا اجتهاده يدخل ضمن السياسة الشرعية وتصرف الامام على الرعية منوط بالمصلحة، وذكر ابو عبيد القاسم بن سلام عن النعان بن زرعة: "أنه سأل عمر بن الخطاب هبلِّن، وكلمه في

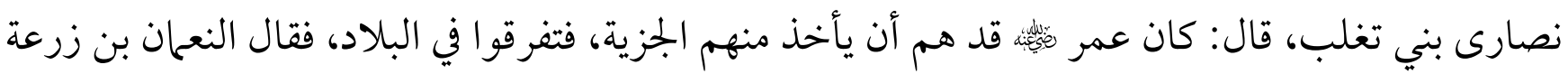
لعمر : يا أمير المؤمنين ان بني تغلب قوم عرب يأنفون من الجزية، وليست لهم أموال، انما هم اصحاب حروث

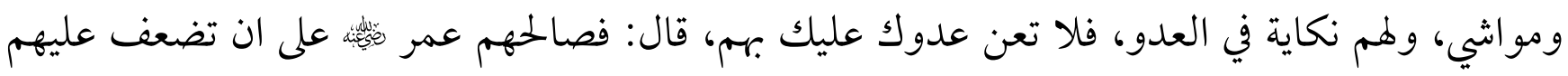
الصدقة، واشترط ان لا ينصرو أو لادهم"(116). هذا رأي فقهي سياسي تصرف فيه الخليفة وهو الحاكم للدولة بحا تقتضيه المصلحة حين درأ القتل عنهم، وقبل منهم امو الهم، ولم يجعلها جزية كسائر ما على أهل الذمة، ولكن جعلها صدقة مضاعفة، وانما استجازها فيما نرى وترك الجزية مما رأى من نفورهم وأنفهم، فلم يأمن شقاقهم واللحاق بالروم، فيكونوا ظهيراً على اهل الاسلام، وعلم انه لا ضرر على المسلمين من اسقاط ذلك الاسم عنهم (117).

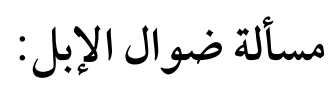




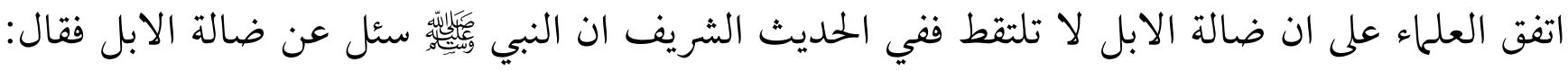
"مالك ولها، دعها فان معها حذاءها وسقاءها، ترد الماءوتأكل الشجر حيث ييدها ربها"(118).

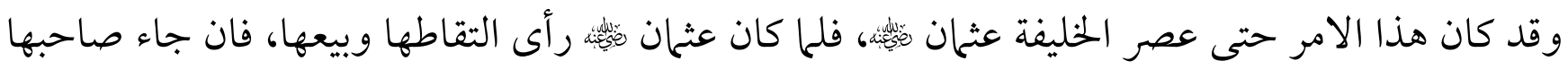
أخذ ثمنها. قال ابن شهاب الزهري: "كانت ضوال الابل في زمن عمر بن الخطاب إبلاً مؤبلة حتى كان زمان عثمان بن عفان امر بتعريفها ثم تباع، فإذا جاء صاحبها أعطي ثمنها" (119).

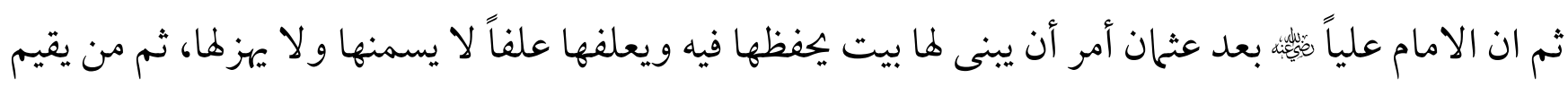
البينة على أنه صاحب شيء منها تعطى له، والا بقيت على حالها لا يبيعها(120). فان ما فعله عثمان وعلي (رضي الله عنها) لم يكن مخالفة منها للنص الشرعي بل نظر الى مقصوده، فحيث تغيرت اخلاق الناس ودب فيهم فساد الذمم، وامتدت ايدي بعضهم الى الحرام، فكان ترك ضوال الابل

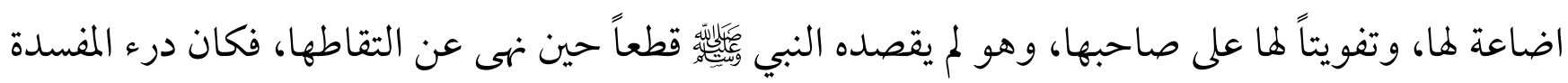
متعيناً في ذاتها مصلحة متحققة لصاحبها(121). وبالتالي فان هذا الر أي الشرعي الذي اتخذه عثمان وعلي (رضي الله عنها) لما رآه من مصلحة مرسلة لم يشهد لها بالاعتبار شاهد خاص بل يدخل ضمن المقصد العام وهو حفظ المال، وهذا الموقف بحكم ولا ينهى عنها المسلمين.

المطلب الثاني: أثر المصلحة المرسلة يِّ السياسـة الشرعية عند الفقهاء والمذاهب: جمهور الفقهاء متفقون على أن المصلحة اساس صالح لتشريع الاحكام الفقهية، غير ان جمهور الحنفية و الشافعية يشترطون في المصلحة ان تكون داخلة تحت القياس، بحيث وجد اصل معين يقاس عليه وتوجد فيه علة منضبطة يكون في ربط الحكم بها مظنة تحقق المصلحة، وعلى هذا فهم يقفون عند المصالح المعتبرة، ولكنهم يتوسعون في اعتبار المصالح لتوسعهم في اعتبار الشارع للعلل التي يناط بها الحكم تحقيقاً للمصلحة، بحيث لا 
تكاد توجد مصلحة مرسلة لا يوجد شاهد باعتبارها، وقد ذهب الشافعي ومن تابعه الى انه لا استباط بالاستصلاح، ومن استصلح فقد شرع كمن استحسن، والاستصلاح كالاستحسان متابعة للهوى. ويزداد الحنفية عن الشافعية في هذا المجال لاعتمادهم على الاستحسان الذي يستند في بعض الاحيان على المصلحة. اما المالكية فقد حدد الشاطبي ذلك بقوله: "بأنها التي سكتت عنها النصوص لكنها ملائمة لتصرفات الشرع، بان اعتبارها في الجملة بغير دليل معين وليست هي المصلحة المسكوت عنها ولا عهد لتصرفات الشارع (122)" r.

ويقول أيضاً: "أما قسم العادات الذي هو جار على المعنى المناسب الظاهر للعقول فانه استرسل فيه استرسال المدل العريق فيفهم المعاني المصلحية، نعم مع مراعاة مقصود الشارع، ألا يخرج عنه ولا يناقض أصلاً من أصوله، حتى استشنع كثر من العلماء وجوه استرساله زاعمين أنه خلع الرقية وفتح باب التشريع، وهيهات ما أبعده عن ذلك (رحمه الله)، بل هو ذلك الذي رضي لنفسه في فقهه بالاتباع"(123). وقد نقل الشوكاني عن ابن دقيق العيد قوله: "الذي لا شك فيه ان لمالك ترجيحاً على غيره من الفقهاء في هذا النوع، ويليه احمد بن حنبل ولا يكاد يخلو غيرهما من اعتباره في الجملة، ولكن لهذين ترجيح في الاستعحال لها على غيرها"(124). لقد ذهب الامامان مالك واحمد بن حنبل ومن تبعها الم ان الاستصلاح طريق شرعي لاستنباط الحكم فيما لا نص فيه ولا اجماع، وأن المصلحة المطلقة التي لا يو جد من الشرع ما يدل على اعتبارها ولا على الغائها مصلحة صالحة لان يبنى عليها الاستنباط، كما انهم يجعلونها دليلاً مستقلاً بعنوان المصلحة المرسلة، او بعنوان الاستصلاح أي طلب فيه مصلحة، كما جاء في تعبير الغزالي، او بعنوان الاستدلال كما يسميها امام الحرمين، ويضعون الشروط للتشريع على اساسها، ولذا اشتهر ان الاحتجاج بالمصلحة المرسلة هو منهج المالكية والحنابلة، دون الحنفية والشافعية. ونذكر بعض الامثلة عند المذاهب على المصلحة المرسلة في السياسة الشرعية لبيان اثرها: 
ما روي عن الامام ابي حنيفة (رحمه الله) من عدم قبول توبة الزنديق اذا تاب بعد القبض عليه، جاء في الحاشية: "اذا اخذ الساحر او الزنديق المعروف الداعي قبل توبته، ثم تاب لم تقبل توبته ويقتل "(125)، وعلق ابن عابدين على ذلك قائلاً: "وهو قياس ابي حنيفة وهو حسن جداً"(126). حكم الأحناف بميراث زوجة الفار معاملة بنقيض مقصوده، وذلك وارد حله في الشرع بحرمان القاتل منه الميراث، ذكر ابن نجيم تحت عنوان "من استعمل الشيء قبل اوانه عوقب بحرمانه" فقال: "ومن فروعها حرمان القاتل مورثه من الارث، ومن فروعها لو طلقها ثلاثاً بلا رضاها قاصداً حرمانها من الإرث في مرض بـ موته فإنها ترثه"(127)، واستحسان ابي يوسف توريث زوج المرتدة منها اذا ارتدت في مرض موتها، والمصلحة فيه معاملتها بنقيض مقصودها"(128). روى ابو يوسف عن الامام أبي حنيفة: "واذا اصاب المسلمون غنائم من متاع او غنم فعجزوا عن حمله ذبحوا الغنم، وحرقوا المتاع، وحرقوا لحم الغنم، كراهية ان ينتفع بذلك اهل الشرك ... وهي فتوى ملحوظ فيها رعاية مصلحة المسلمين، بدفع المفسدة التي تترتب على ترك هذه الغنائم في ايدي اعدائهم يثقون بها"(129). والخلاصة ان معظم العلل التي اعتمد عليها الحنفية استنبطواها من الاصول العامة للشريعة، ويقول ابو زهرة عن تطبيقات الحنفية في المصالح المرسلة "والاستحسان من غير نص او قياس خفي اخذ بالمصلحة"(130). ثانياً: المالكية: تنصيب الامثل من غير المجتهدين اماماً، اذا لم يوجد مجتهد، لان ترك الناس دون امام فوضى تبعث على الهرج و الفساد، وليس في تنصيب مثله اماماً من فساد إلا فوت الاجتهاد و التقليد كان حينئذ(131). اجازة بيعه المفضول، وهو الذي يوجد من هو افضل منه بالخلافة، لأن بطلانها يؤدي الم فساد واضطراب في الامور، والى عدم اقامة مصالح الناس في الدنيا، وفوضى ساعة يرتكب فيها المظالم ما لا يرتكب في ظلم سنين، وقد أثر عن الامام مالك أنه قال في عدم عهد عمر بن عبد العزيز بالخلافة من بعده المى رجل: "انما كانت البيعة 
ليزيد بن عبد الملك من بعده فخاف عمر ان ولى رجالًا صالحاً الا يكون ليزيد بد من القيام، فتقوم فتنة فيفسد ما لا يصلح" (132).

جواز التسعير وتلقي الركبان، وفتوى الامام مالك (رحمه الله تعالى) في هذين الفرعين ليست على خلاف النص، وانما تطبيق للنص، واستخر اج لمناطه بطريق الاجتهاد، ومثل هذا النوع من الاجتهاد يتفق الائمة على سلوكه، واستنباط الاحكام بناء عليه، وهذا التطبيق للنص نفسه، وتفسير له بالمعنى المناسب او المصلحة السابقة المى الفهم من ذات النص لا من خارجه، فإذا تقررت هذه القاعدة فنقول ان جواز التسعير عند الحاجة،

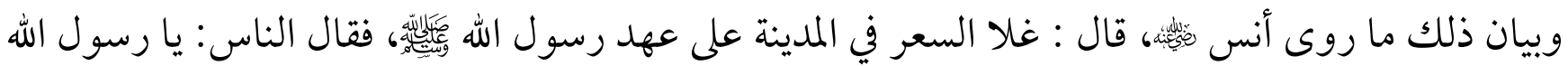
سعر لنا، فقال رسول الله وَكَيليَّة: "ان الله هو المسعر القابض الباسط الرزاق اني لأرجو ان ألقى ربي وليس أحد

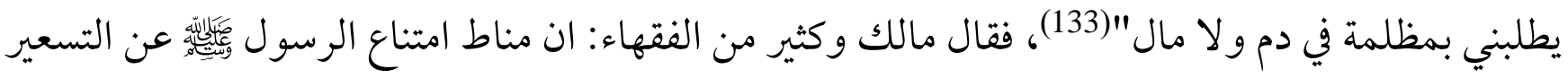
ليس كونه تسعيراً، وانها لما فيه من الظلم للتجار فيه، اما اذا التجأ المى الحيل والاحتكار، واخفوا السلع طمعاً في الكسب المحرم، والربح الخبيث، مستغلين حاجة العامة الى الطعام، فان القاضي يفتي بجواز التسعير في هذه الحالة منهي عنه، ذلك ان مناط النهي غير متحقق في هذه الحالة ؛ لان ارتفاع السعر هنا بفعل التجار والثمن يزيد عن المثل (134). ثالثاً: الثافعية: قال العز بن عبد السلام: "لو عم الحرام في بلدة بحيث لا يوجد فيها حلال، جاز ان يستعمل من ذلك ما تدعو اليه الحاجة، ولا يقف تحليل ذلك على الضرورة، لأنه لو وقف عليها لأدى الى ضعف العباد، واستيلاء الكفار و اهل العناد على بلاد الاسلام، ولا ينقطع الناس عن الحرف و الصنائع والاسباب التي تقوم بمصالح الأنام، ومن تبع مقاصد الشرع في صلب المصالح ودرء المفاسد حصل له من بجموع ذلك اعتقاد أو عرفان بأن هذه المصلحة لا يجوز اهمالها، وأن هذه المفسدة لا ييجوز قربانها، وإن لم يكن فيها اجماع، ولا نص، ولا قياس خاص فان فهم نفس الشرع بوجب ذلك"(135). 
يجيز الشافعية اتلاف الحيوان الذي يقاتل عليه الكفار، واتلاف شجرهم ونباتهم، لحاجة القتال والظفر بهم، وييوزون كذلك أخذ نبات الحرم لعلف البهائم، لمالـ يلحق الحجيج من الحرج لو لم يبح لمم (136). ما جاء في كتاب الأم ان الرجوع عن الشهادات ضربان، فاذا شهد الشاهدان او الشهود على رجل بشيء يتلف من بدنه او ينال مثل قطع او جلد او قصاص في قتل او جرح، وفعل به ذلك، ثم رجعوا فقالو ا: عمدنا أن ينال منه ذلك بشهادتنا فهي كالجنابة عليه، وما كان فيه من ذلك قصاص خير بين ان يقتص أو يأخذ العقل، وما لم يكن فيه من ذلك قصاص اخذ فيه العقل وعزروا دون الحد (137). رابعاً: الحنابلة: وقد وردت عن الامام احمد (رحمه الله تعالى) فتاوى عديدة بينت على المصلحة وحدها، ومنها(138): نفي اهل الفساد والدعارة الى بلد يؤمن فيه من شرهم. تغليظ الحد على شارب الخمر في نهار رمضان. اجبار اهل الصناعات عليها بأجر المثل، اذا احتاج الناس الى صناعتهم، او كما قال ابن القيم: "ومن ذلك ان يجتاج الناس الى صناعة طائفة كالفلاحة والنساجة والبناء وغير ذلك، فلولي الأمر أن يلزمهم بذلك بأجرة مثلهم، فانه لا تتم مصلحة الناس الا بذلك"(139).

$$
\text { - فهذه اهم النتائج التي توصلت اليها في بحثي هذا وهي كالآتي: }
$$
- ان الشارع قد شرع من الاصول الكلية والقواعد المنهجية ما يجعل باب الاجتهاد مفتوحاً لكل ما يستجد من قضايا ووقائع في حياة الناس تحقيقاً للمقصد الأعظم من التشريع وهو جلب المصالح ودرء المفاسد. - يتضح من دراسة أصل المصلحة المرسلة أنها معتبرة عند معظم الفقهاء يقولون بها ويفتون بناء عليها، ولكنهم يختلفون في المصطلح الذي يطلقونه عليها. 
- - السياسة الشرعية سلطة تقديرية ممنوحة للحاكم شرعاً يعمل بها على تدبير شؤون الامة بحا يجقق مصلحتها ومصلحة شعبها.

- لولي الامر السلطة الكاملة في منع بعض المباحات أو توقيفها المى حين أو التقييد استناداً الم المصلحة المرسلة إن رأى في ذلك تحقيق مصلحة راجحة ودرء مفسدة واقعة للفرد او المجتمع، ولهذا كان اكثر استعج|ها في السياسة الشرعية. - - احكام السياسة الشرعية غير ثابتة فاذازالت المصلحة التي بني عليها زال الحكم ووجب تغيرها. - اهمية المصالح المرسلة وحاجة الفقيه المجتهد الى اعتبارها في فهم الاحكام والقيام بالتكاليف واداء الاحكام.

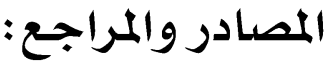

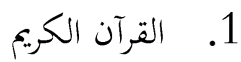

2.

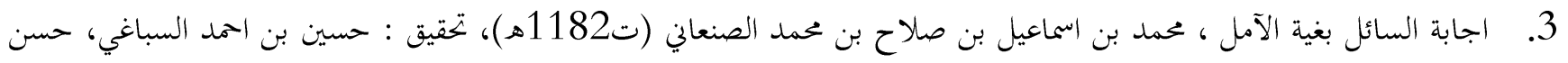

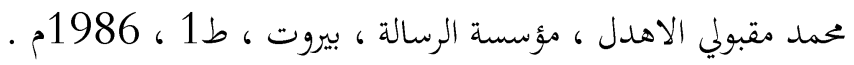

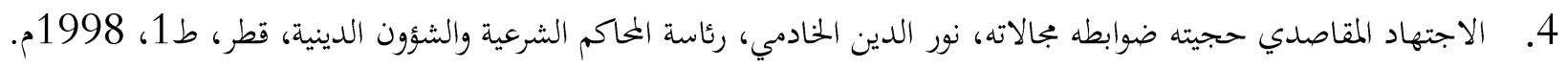

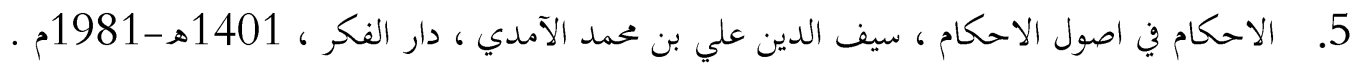

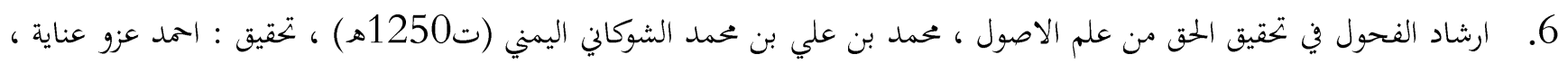

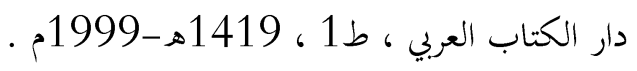

7.

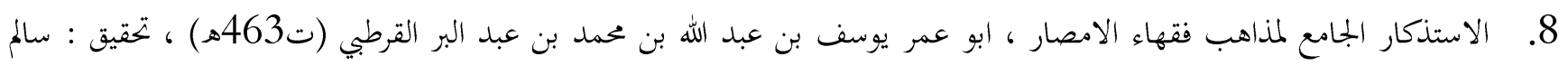

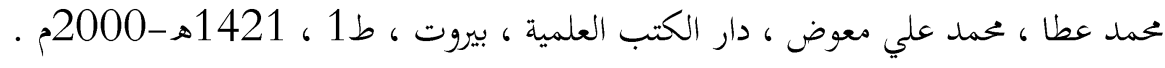

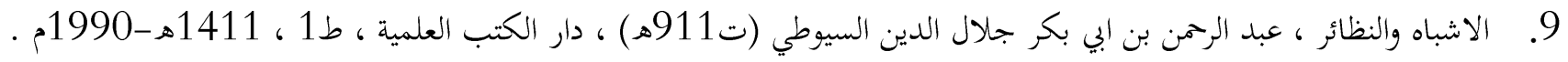

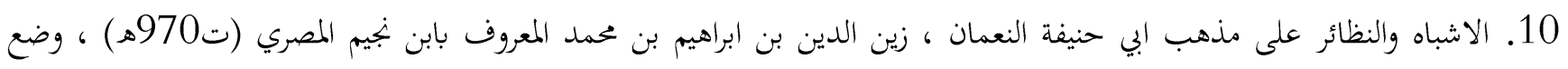

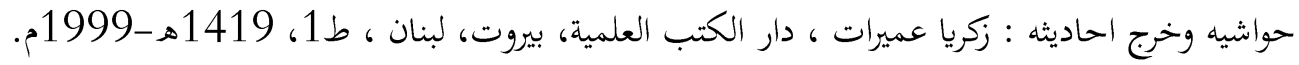

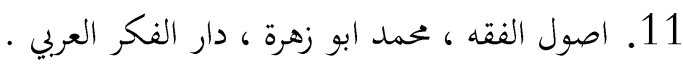


12. الاعتصام، ابراهيم بن موسى بن محمد الغرناطي الشهير بالشاطبي (ت790ه)، تحقيق: سليم بن عبد الهلالي، دار ابن عفان،

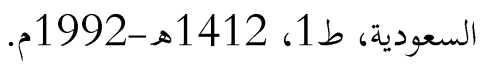

13. اعلام الموقعين عن رب العالمين ، محمد بن ابي بكر بن ايوب بن سعد شمس الدين بن قيم الجوزية (ت 751هـ) ، دار الكتب العلمية ،

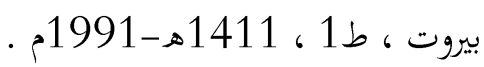

14. الام ، محمد بن ادريس الشافعي (ت204هـ) ، دار المعرفة ، بيروت ، 1410هـ-1990م ،

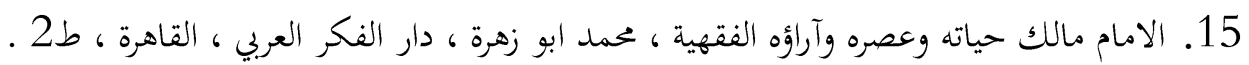

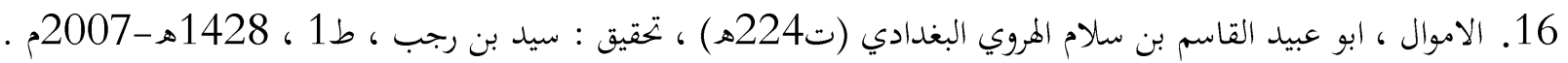

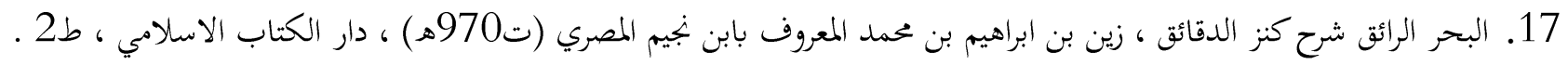

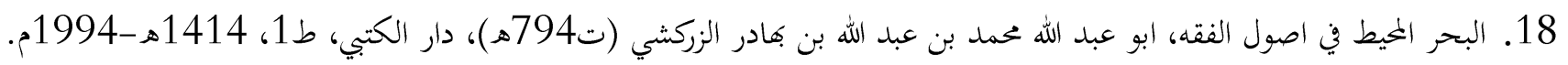

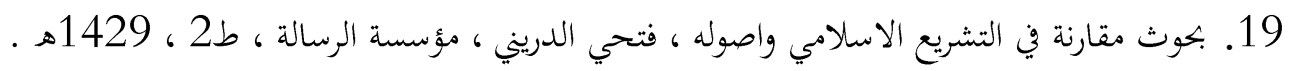

20. بداية المجتهد وهاية المقتصد، ابو الوليد محمد بن احمد بن محمد بن رشد القرطبي (ت

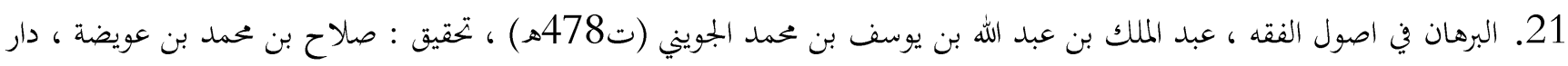

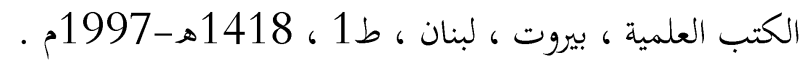

22. تاج العروس ، محمد بن محمد بن عبد الرزاق الحسيني الملقب بمرتضى الزبيدي ، دار الهداية .

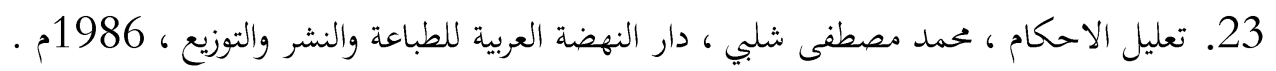

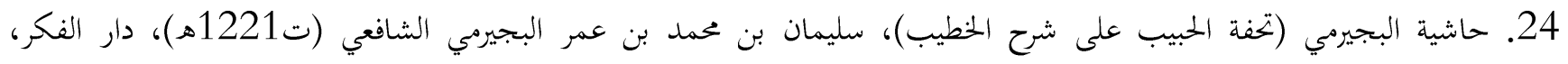

. 1995-1415

25. خصائص التشريع الاسلامي ، الدكتور فتحي الدريني ، مؤسسة الرسالة .

26. الرأي واثره في الفقه الاسلامي ، ادريس جمعة درار .

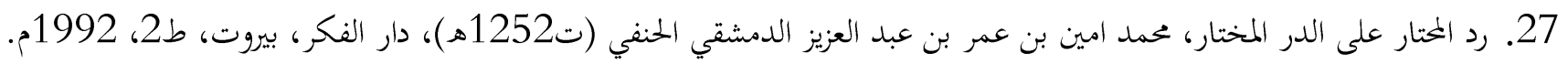

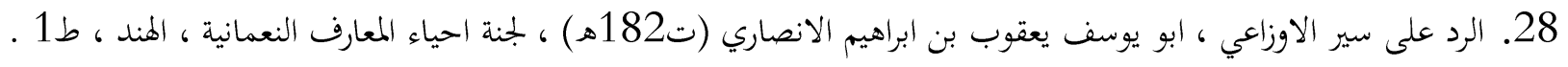

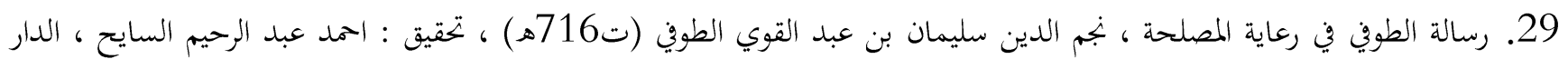

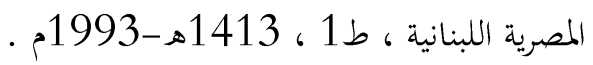

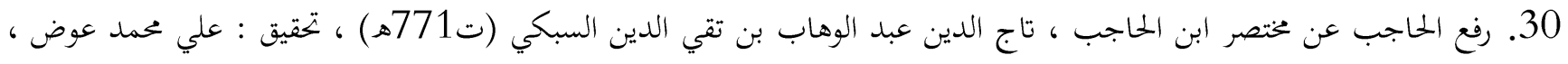

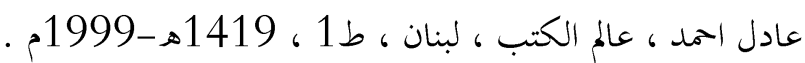

31. سنن ابن ماجة، ابو عبد الله محمد ين يزيد القزويني ابن ماجة (ت273 27هـ)، تحقيق: محمد فؤاد عبد الباقي، دار احياء الكتب العربية.

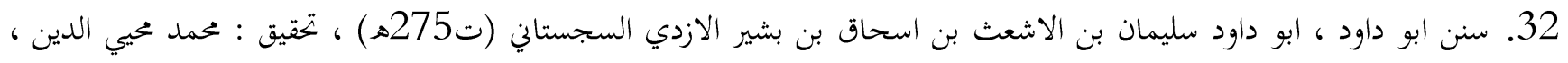

المكتبة العصرية ، صيدا ، بيروت .

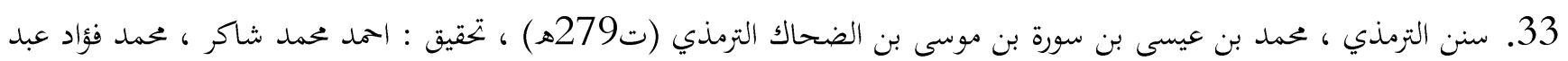

الباقي ، ابراهيم عطوة عوض ، شركة مكتبة ومطبعة مصطفى البابي الحلبي ، مصر ، ط2 ، 1395هـ-1975م . 
34. السياسة الشرعية في الشؤون الدستورية والخارجية والمالية ، عبد الوهاب خلاف (ت1375هـ) ، دار القلم ، 1408هـ-1988م .

35. السياسة الشرعية وقواعدها فيما لا نص فيه ، محمد خالد منصور .

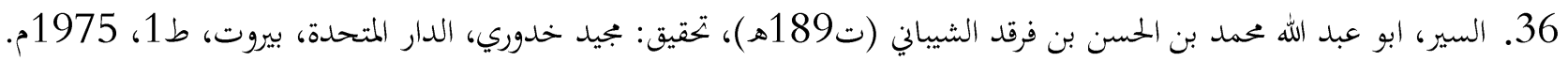

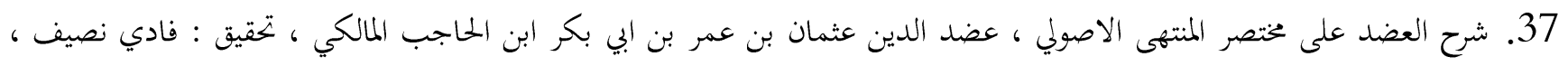

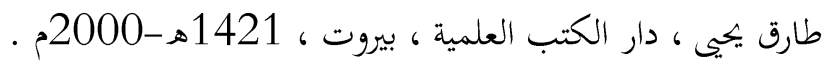

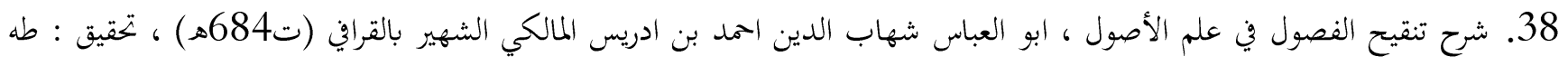

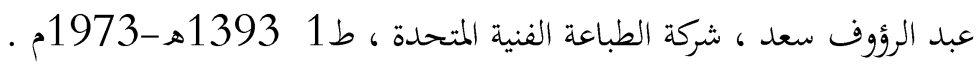

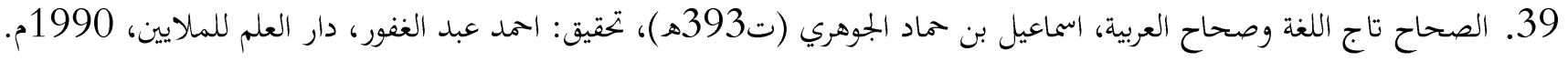

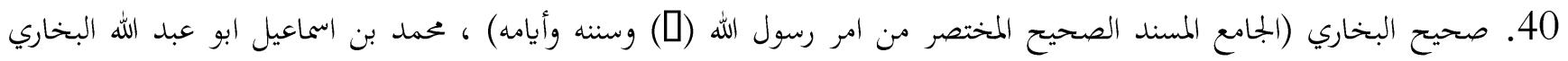

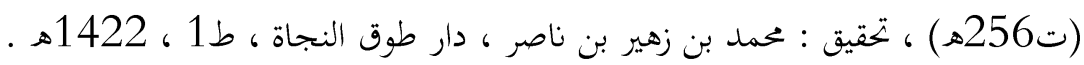

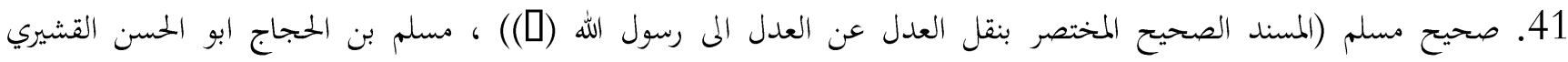

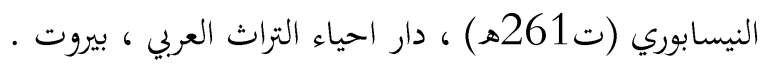

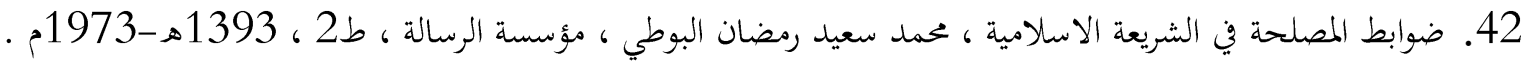

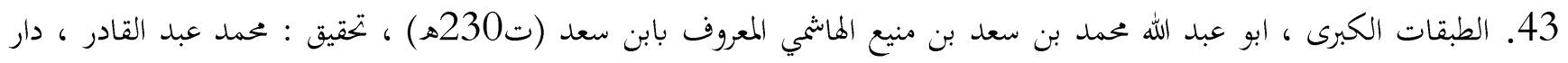

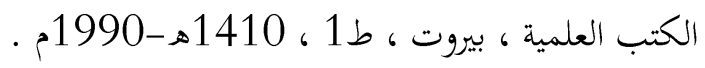
44. الطرق الحكيمة في السياسة الشرعية ، محمد بن ابي بكر بن قيم الجوزية (ت151 751) ) ، مكتبة دار البيان .

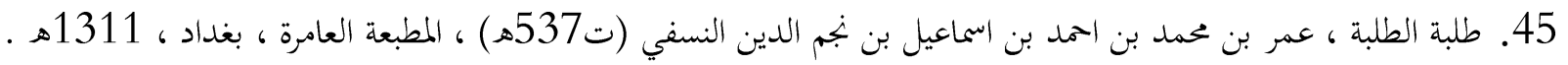

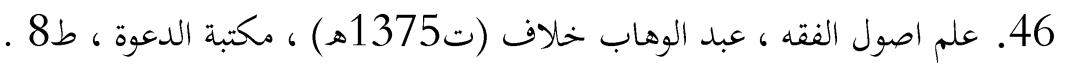

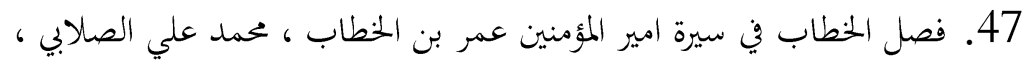

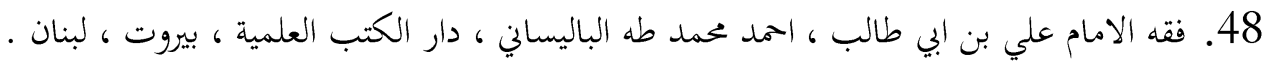
49. القاموس الميط ، محمد بن يعقوب الفيروز آبادي ، مؤسسة الرسالة ، بيروت .

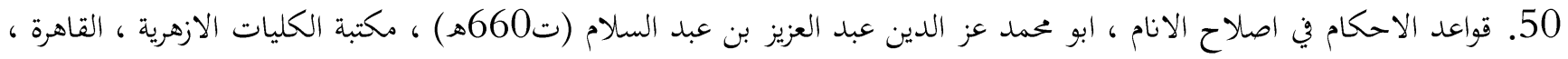

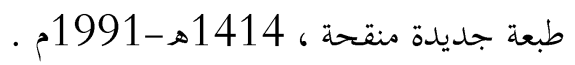

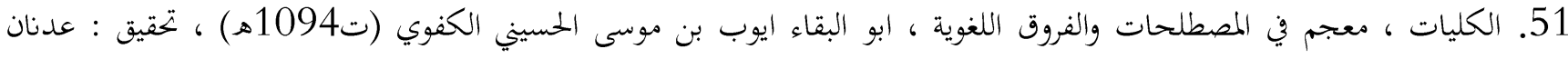

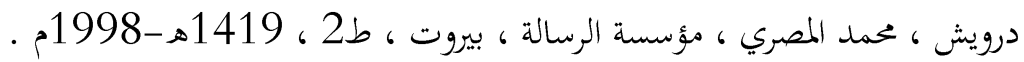

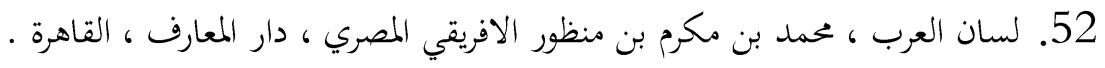

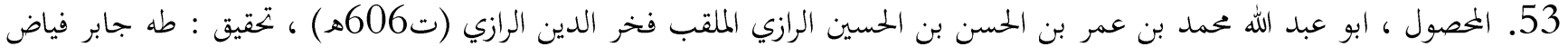

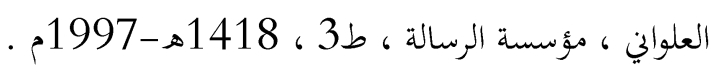

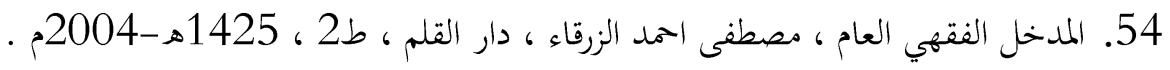

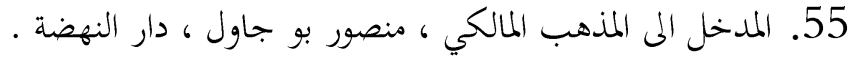


56. المستصفى في علم الاصول، ابو حامد محمد الغزالي (ت505هـ)، تحقيق: محمد بن عبد السلام، دار الكتب العلمية، ط1، 1413هـ.

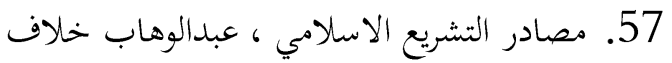

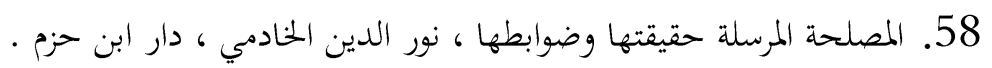

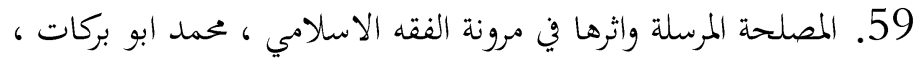

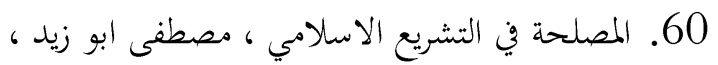

61. المصنف في الاحاديث والآثار، ابو بكر بن ابي شيبة عبد الله بن محمد بن ابراهيم العيسى (ت235هـ)، تحقيق: كمال يوسف الحوت،

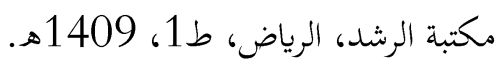

62. المعجم الوسيط ، مجمع اللغة العربية بالقاهرة ، ابراهيم مصطفى ، احمد الزيات ، حامد عبد القادر ، محمد النجار ، دار الدعوة .

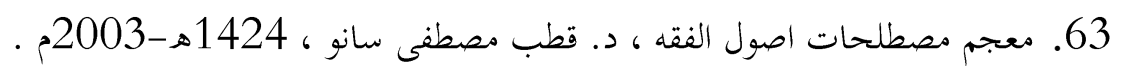

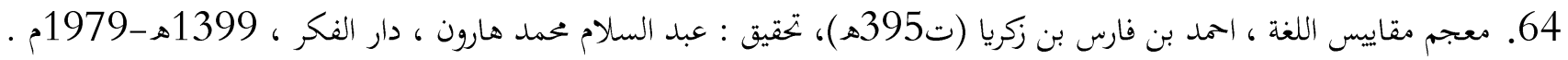

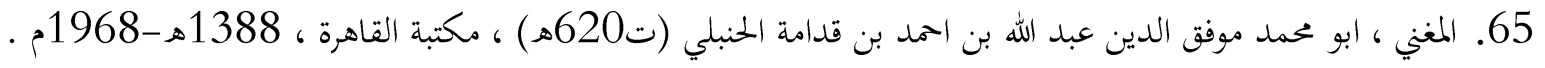

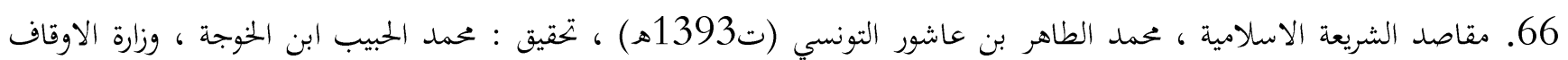

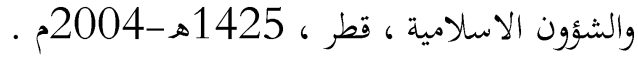

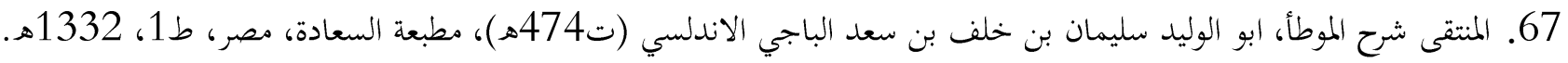

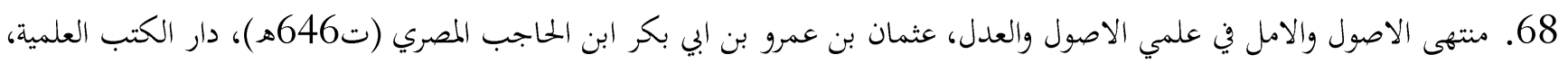

69. الموافقات في اصول الشريعة، ابراهيم بن موسى بن محمد الغرناطي الشهير بالشاطبي (ت790ه)، تحقيق: ابو عبيدة مشهور بن حسن،

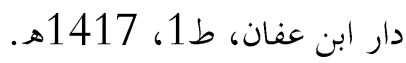

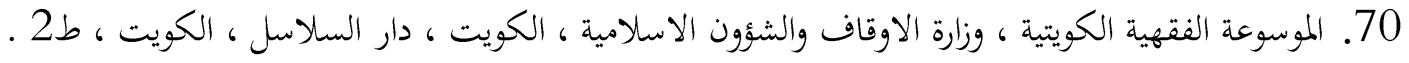

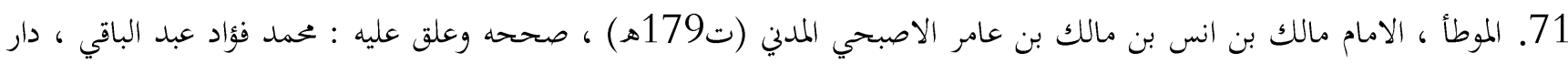

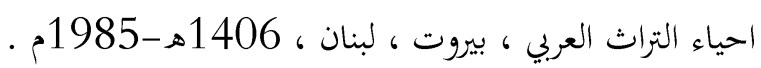

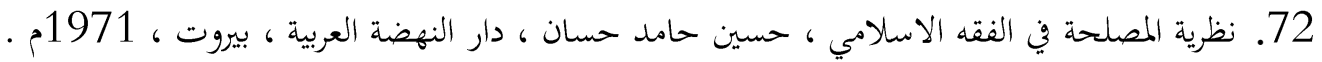

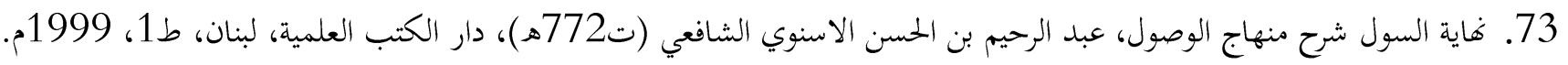

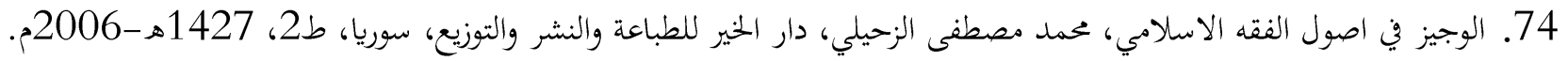

\section{الهوامش:}

(1) معجم مقاييس اللغة ، 303/3 ، مادة صلَح . 
(2) ينظر: لسان العرب، ابن منظور، 462/2؛ القاموس الميط، 235/1؛ الصحاح، الجوهري، 564/1؛ تاج العروس، الزبيدي،

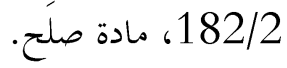

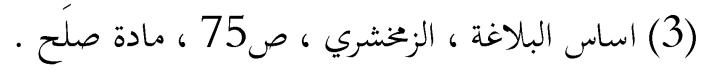

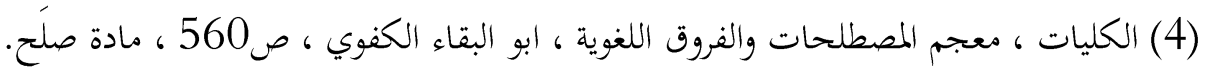

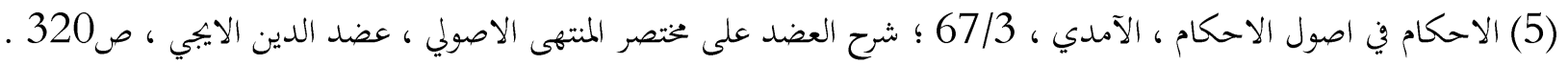

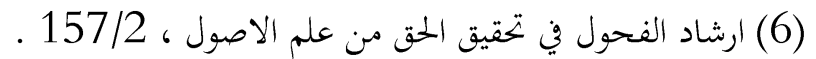

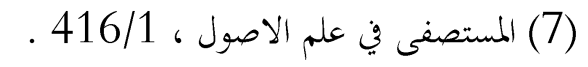

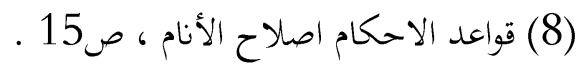

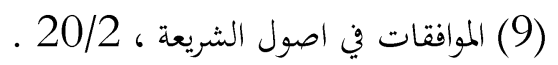

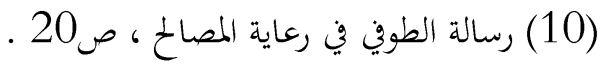

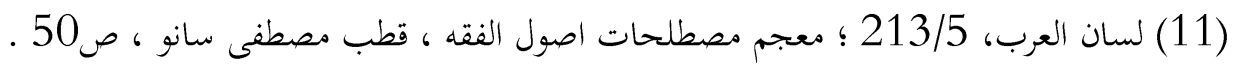

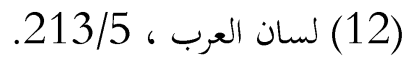

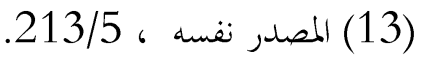

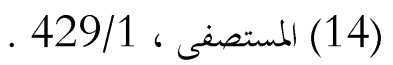

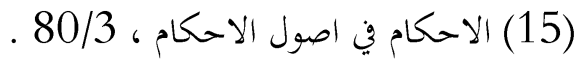

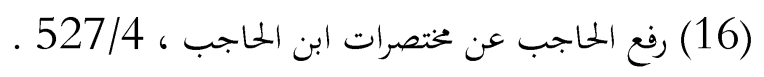

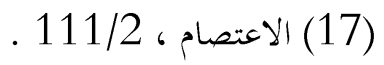

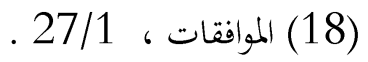
(19) ينظر : منتهى الوصول والأمل في علم الاصول والجدل ، ص288 ، 2711 ،

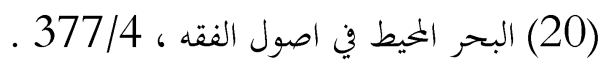

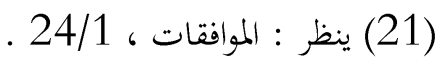
(22) ضوابط المصلحة في الشريعة الاسلامية ، ص305 ـ الموات

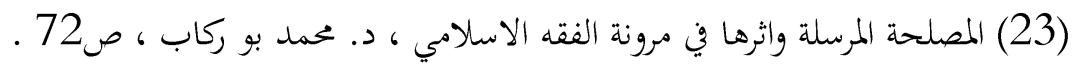

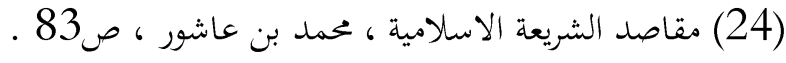

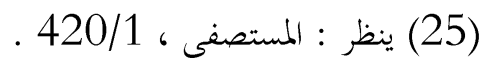

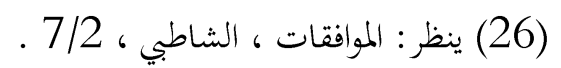

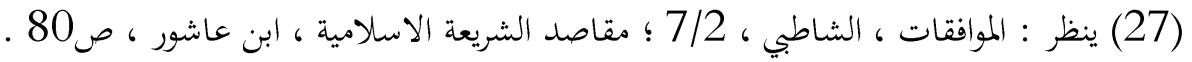

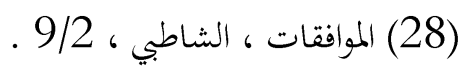

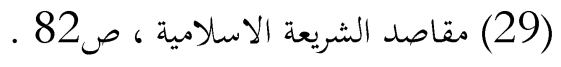




$$
\begin{aligned}
& \text { (30) ينظر : الموافقات ، الشاطبي ، 9/2-10 . }
\end{aligned}
$$

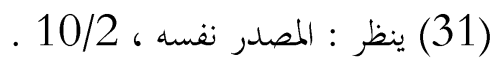

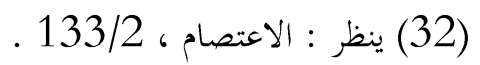$$
\text { (33) (33) المستصفى ، 4320/1) }
$$

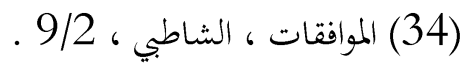

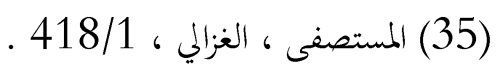

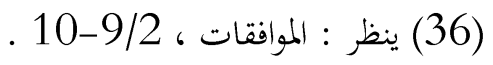

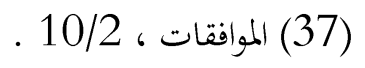

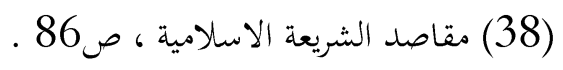

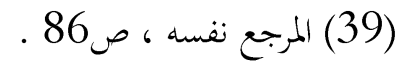

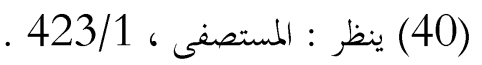

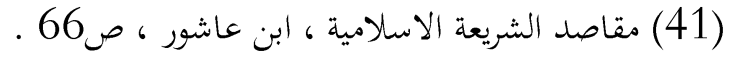

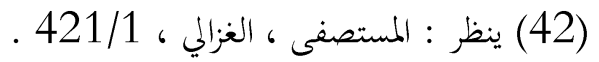

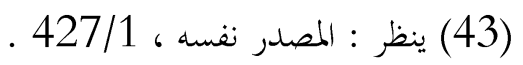

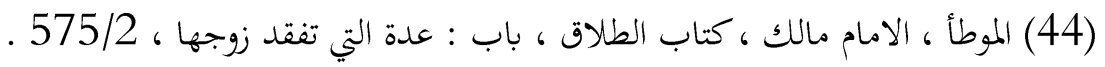

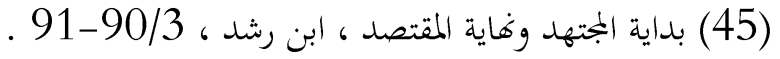

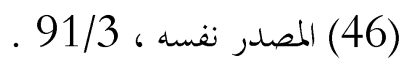

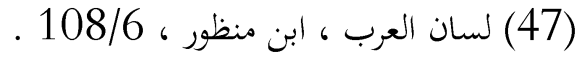

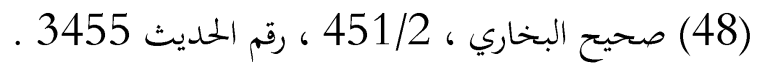

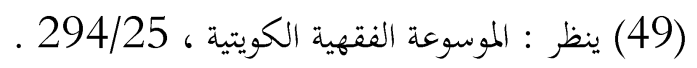

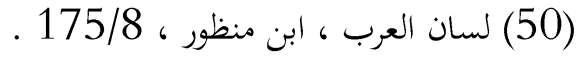

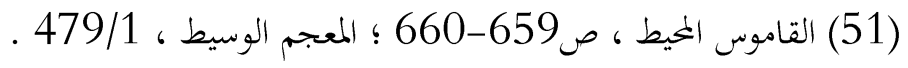

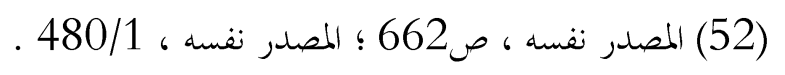

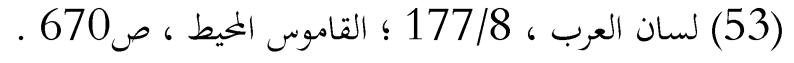

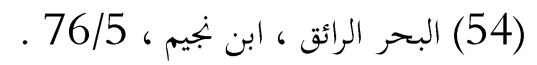

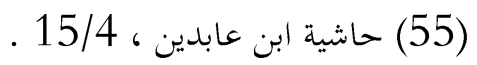

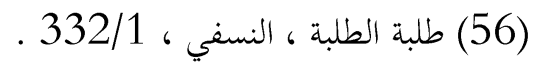

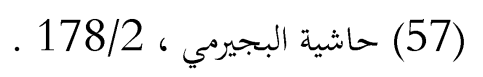

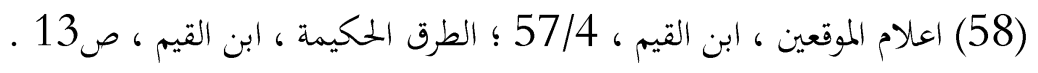




$$
\begin{aligned}
& \text { (60) خصائص التشريع الاسلامي ، الدريني ، ص191 . }
\end{aligned}
$$

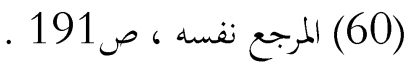

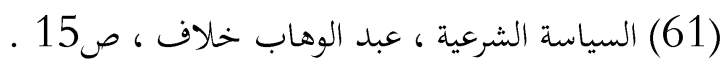

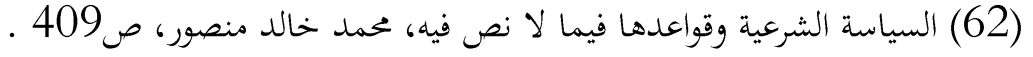

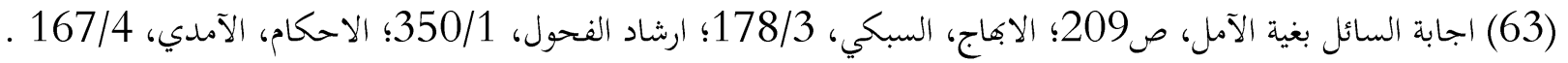

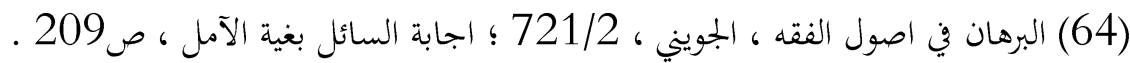

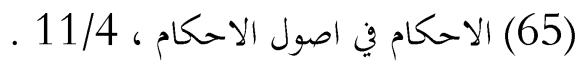

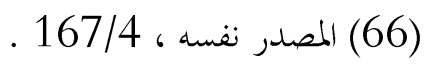

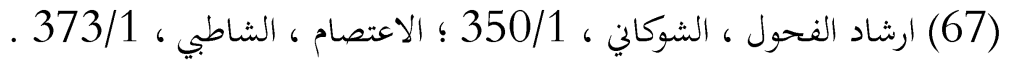

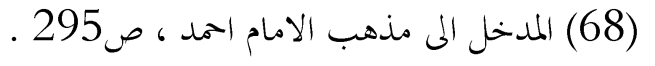

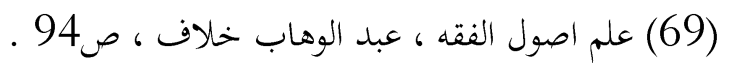

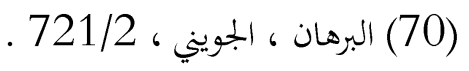$$
\text { (71) غاية السول شرح منهاج البيضاوي ، 859/2 ، اليوني ، }
$$

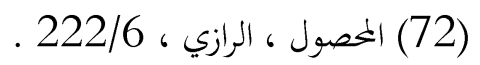

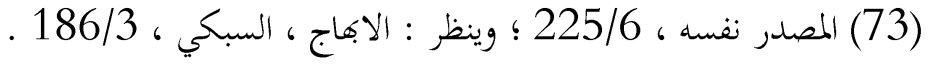

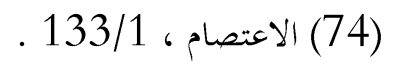

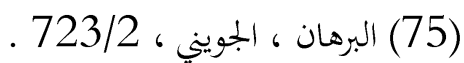

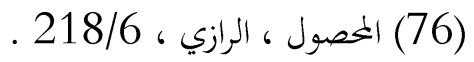

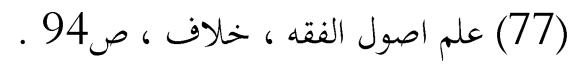

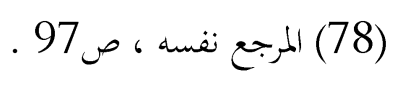

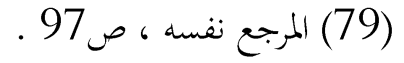

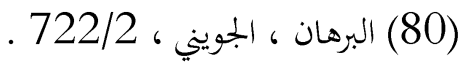

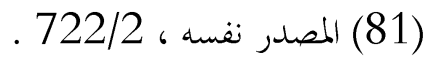

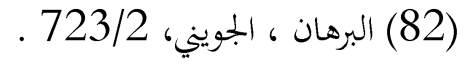

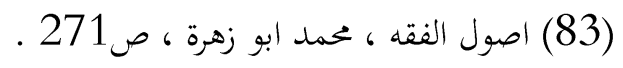

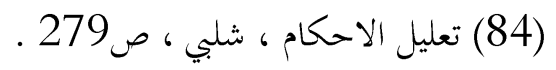

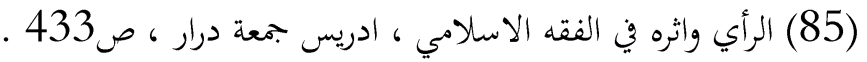

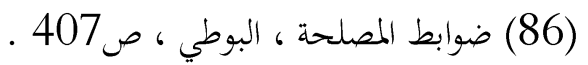

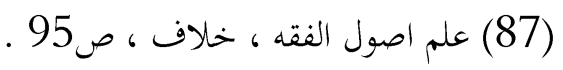




$$
\begin{aligned}
& \text { (88) مصادر التشريع الاسلامي ، خلاف ، ص85 . }
\end{aligned}
$$

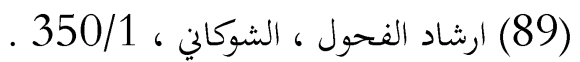

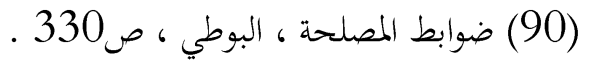

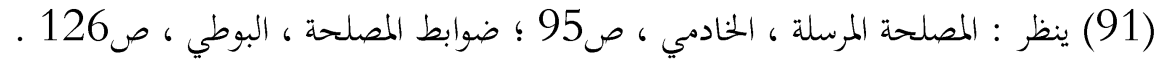

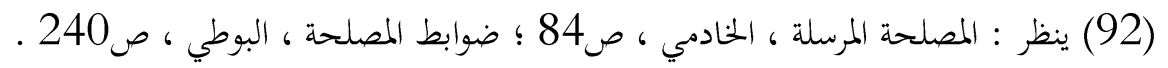

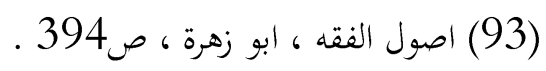

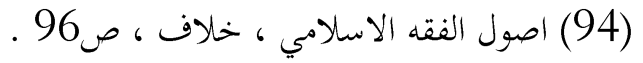

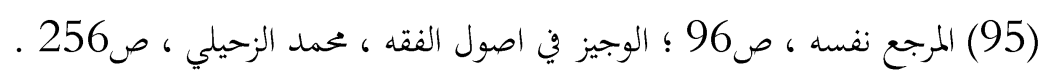

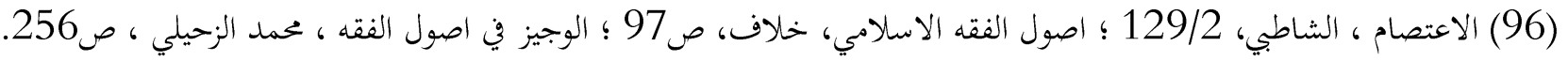

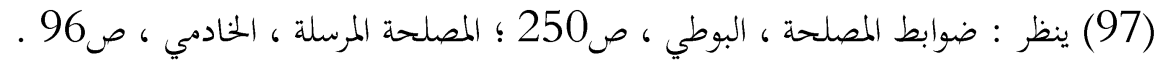

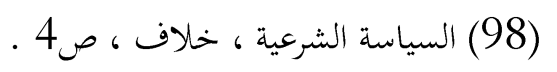

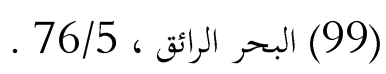

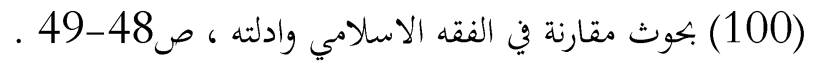

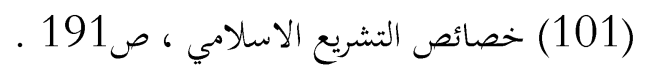

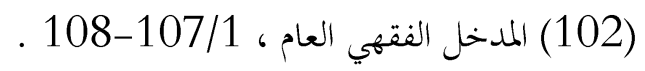

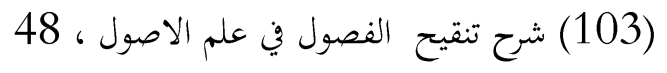

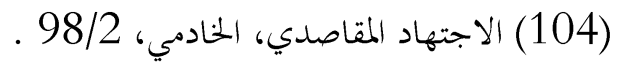

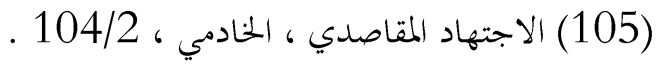

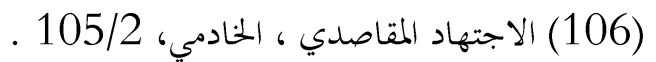

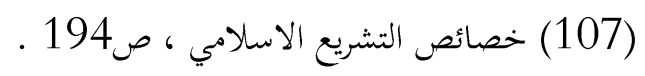

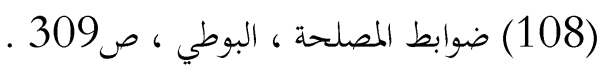

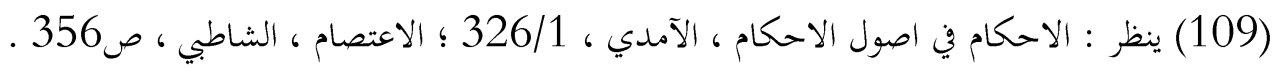

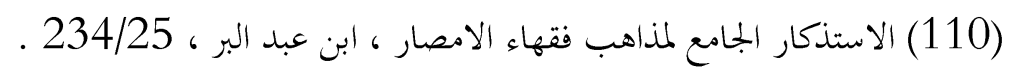

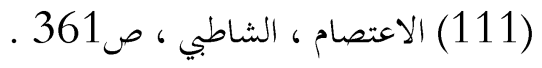

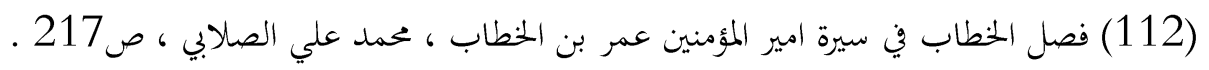

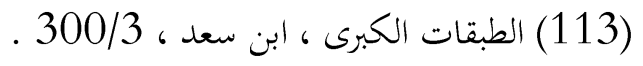

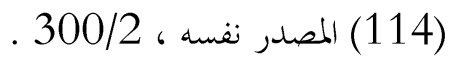

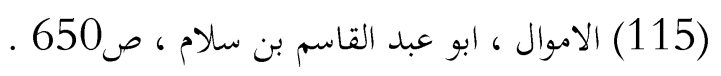

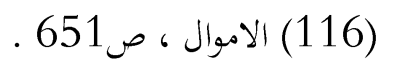




$$
\begin{aligned}
& \text { (117) ينظر : المصدر نفسه ، ص651 ؛ المغني ، ابن قدامة ، 277/9 ـ }
\end{aligned}
$$

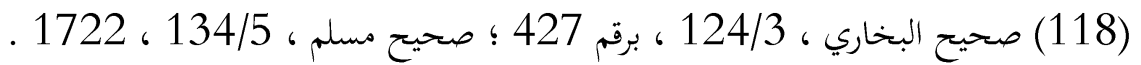

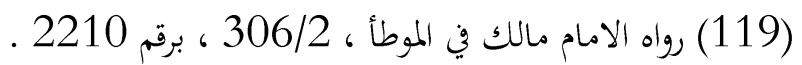

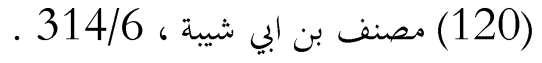

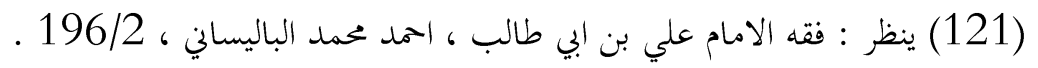

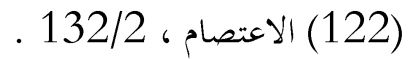

$$
\begin{aligned}
& \text { (133/2) المصدر نفسه (123) (123) }
\end{aligned}
$$

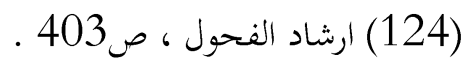

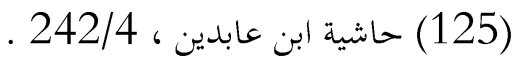

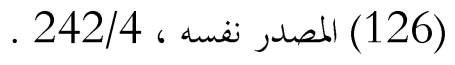

$$
\begin{aligned}
& \text { (127) الاشباه والنظائر ، ص80. }
\end{aligned}
$$

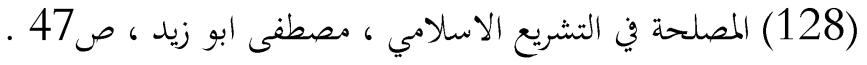

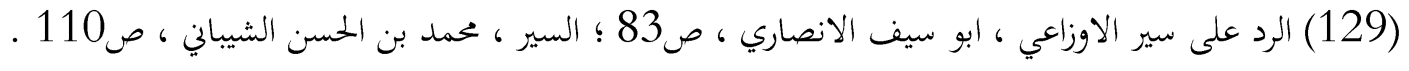

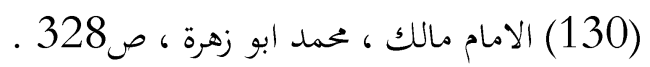

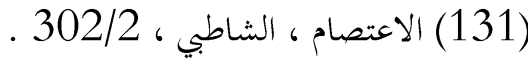

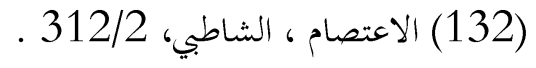

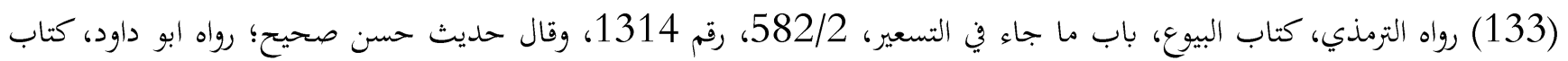

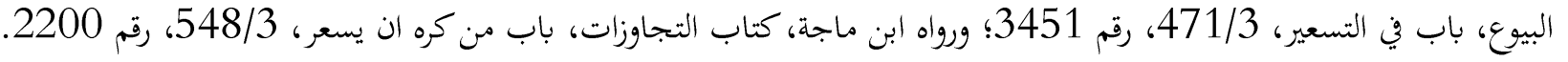

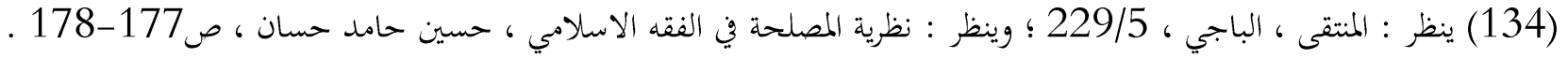

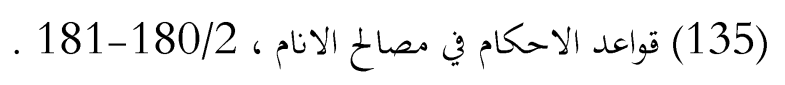

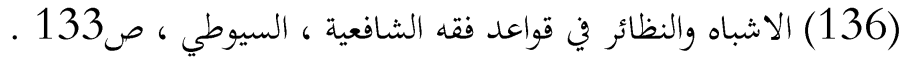

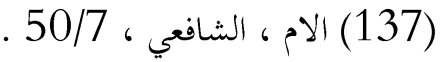

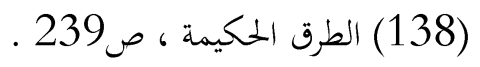

$$
\begin{aligned}
& \text { (139) المصدر نفسه ، ص241 لـ240. }
\end{aligned}
$$

